NBER WORKING PAPER SERIES

THE IMPACT OF FAMILY COMPOSITION ON EDUCATIONAL ACHIEVEMENT

\author{
Stacey H. Chen \\ Yen-Chien Chen \\ Jin-Tan Liu \\ Working Paper 20443 \\ http://www.nber.org/papers/w20443 \\ NATIONAL BUREAU OF ECONOMIC RESEARCH \\ 1050 Massachusetts Avenue \\ Cambridge, MA 02138 \\ August 2014
}

The authors thank to the Ministry of Interior Affairs and the Joint Board of the College Recruitment Commission for providing administrative data. We benefited from feedback from Josh Angrist, John Ham, Yu-Chin Hsu, Masao Ogaki, Nancy Qian, Tyler VanderWeele, Francis Vella, anonymous referees, and participants in universities and the 2009 NBER Education and Children Programs. We acknowledge financial support from the Academia Sinica Career Award (103-H02), Taiwan's National Science Council (NSC101-2628-H-001-001-MY3) and National Health Research Institute. The views expressed herein are those of the authors and do not necessarily reflect the views of the National Bureau of Economic Research.

NBER working papers are circulated for discussion and comment purposes. They have not been peer-reviewed or been subject to the review by the NBER Board of Directors that accompanies official NBER publications.

(C) 2014 by Stacey H. Chen, Yen-Chien Chen, and Jin-Tan Liu. All rights reserved. Short sections of text, not to exceed two paragraphs, may be quoted without explicit permission provided that full credit, including $\odot$ notice, is given to the source. 
The Impact of Family Composition on Educational Achievement

Stacey H. Chen, Yen-Chien Chen, and Jin-Tan Liu

NBER Working Paper No. 20443

August 2014, Revised November 2016

JEL No. I20,J13,J16,J24,O10,R20

\section{ABSTRACT}

Parents preferring sons tend to go on to have more children until a boy is born, and to concentrate investment in boys for a given number of children (sibsize). Thus, having a brother may affect child education in two ways: an indirect effect by keeping sibsize lower and a direct rivalry effect where sibsize remains constant. We estimate the direct and indirect effects of a next brother on the first child's education conditional on potential sibsize. We address endogenous sibsize using twins. We find new evidence of sibling rivalry and gender bias that cannot be detected by conventional methods.

Stacey H. Chen

Academia Sinica

Taipei, Taiwan

schen@econ.sinica.edu.tw

Yen-Chien Chen

National Chinan University

Taiwan

Yenchien@ncnu.edu.tw
Jin-Tan Liu

Department of Economics

National Taiwan University

No. 1, Section 4, Roosevelt Road

Taipei (10617), TAIWAN

and NBER

liujt@ntu.edu.tw 


\title{
The Impact of Family Composition on Educational Achievement*
}

\author{
Stacey H. Chen, Yen-Chien Chen, and Jin-Tan Liu
}

October 21, 2016

\begin{abstract}
Parents preferring sons tend to go on to have more children until a boy is born, and to concentrate investment in boys for a given number of children (sibsize). Thus, having a brother may affect child education in two ways: an indirect effect by keeping sibsize lower and a direct rivalry effect where sibsize remains constant. We estimate the direct and indirect effects of a next brother on the first child's education conditional on potential sibsize. We address endogenous sibsize using twins. We find new evidence of sibling rivalry and gender bias that cannot be detected by conventional methods.
\end{abstract}

\section{Introduction}

Gender bias in families has been persisting across generations in many regions. Girls in India, for example, get weaned earlier, receive less childcare and healthcare, and suffer from higher mortality. ${ }^{1}$ However, some studies find no evidence that Indian females receive less care than males under normal circumstances (e.g. Duflo, 2005). Deaton (1997, 2003) suggests that equal parental spending and vaccination were carried out for both genders in the same regions. Using data from Taiwan - a society with a long tradition of preferring sons over daughters ${ }^{2}$ — we also find surprising evidence of females having the advantage in completing high

*S.H. Chen (s-chen@grips.ac.jp): Associate Professor of Economics at National Graduate Institute for Policy Studies (GRIPS). Y.-C. Chen (yenchien@ncnu.edu.tw): Assistant Professor, National Chi-Nan University, Taiwan. J.-T. Liu (liujt@ntu.edu.tw): National Taiwan University and NBER. This is a heavily revised version of Chen, Chen and Liu (2014). Earlier versions of this paper were circulated under the following titles: "We prefer sons, but does it matter? Evidence from matched administrative data from Taiwan," "Estimating the causal effects of sibling gender composition on child mortality and education using twin gender shocks" and "The impact of family composition on educational achievement." Thanks to the Ministry of Interior Affairs and the Joint Board of the College Recruitment Commission for providing administrative data. We benefited from feedback from Josh Angrist, John Ham, Yu-Chin Hsu, Masao Ogaki, Nancy Qian, Tyler VanderWeele, Francis Vella, anonymous referees, and participants in universities and the 2009 NBER Education and Children Programs. We acknowledge financial support from the Academia Sinica Career Award (103-H02), Taiwan's National Science Council (NSC 101-2628-H-001-001-MY3) and National Health Research Institute.

${ }^{1}$ See Chen, Huq and D'Souza (1981), Basu (1989), Sen (1990), Ganatra and Hirve (1994), Borooah (2004), Jayachandran and Kuziemko (2011), Singh (2012), Rosenblum (2013) and Barcellos, Carvalho and Lleras-Muney (2014).

${ }^{2}$ Illustrations of Taiwanese preference for sons include higher death rates among girls during the first half of the 20th century (Barclay, 1954) and fewer opportunities for young women to work or be educated during the postwar period (Greenhalgh, 1985). For more recent evidence, see Parish and Willis (1993) and Lin, Liu and Qian (2014). 
school or attaining university education. ${ }^{3}$

One explanation for these mixed results is that females are more enduring than males given the same care (Waldron, 1983); consequently, gender differences in child outcomes often understate the degree of gender bias. Alternatively, the endowment deficit of males can be canceled out by comparing the sibling gender effect on male versus female outcomes, while keeping the realized number of siblings (sibsize) constant. This strategy has been adopted by the literature on sibling rivalry (or cross-sibling competition). ${ }^{4}$ However, the method of keeping the realized sibsize constant does not work for households that would go on to have more children until they get a son - the so-called son-preferring stopping rule of childbearing (Yamaguchi, 1989; Jensen, 2005; Filmer, Friedman and Schady, 2009). Since households following the son-preferring stopping rule are excluded from estimation, previously estimated effects of gender composition of siblings might have understated the degree of gender bias.

Son preference and the son-preferring stopping rule suggest that having a brother may affect the human capital formation of a boy or a girl in two ways: an indirect effect $(I E)$ by decreasing potential sibsize and a direct effect $(D E)$ where potential sibsize remains constant. Under son preference, $D E$ captures the rivalry effect of a son (relative to a daughter) on child outcomes, keeping other things (including potential sibsize) constant. Under the son-preferring stopping rule, $I E$ captures the gain/penalty from the reduced sibsize by the presence of a brother, keeping other things (including potential sibling gender) constant. If child quality is independent of quantity, then $I E$ is zero. However, if child quality decreases with quantity, then $I E$ is positive. Because $D E$ and $I E$ may go in opposite directions, the overall impact of a brother on child outcomes can appear to be too small, particularly in countries with strong pro-son bias. ${ }^{5}$ Therefore, understanding the relative importance of $D E$ and $I E$ is necessary in detecting gender discrimination.

Given that the gender composition of the existing children affects fertility choice, the conventional methods of "keeping the realized sibsize constant" creates bad-control problems, which not only understate $D E$ but also leave $I E$ undefined (because no variation in sibsize is left for defining $I E$, after the realized sibsize has been fixed). Since $I E$ has not been formulated in the existing literature on gender bias, the relative magnitude of $I E$ to $D E$ is still an open question.

Rather than keeping the realized sibsize constant, new methods have been proposed recently to address the bad-control problem. The most notable work comes from Barcellos, Carvalho and Lleras-Muney (2014), who shut down the $I E$ channel by restricting their sample to infants under 15 months of age. This strategy

\footnotetext{
${ }^{3}$ Rudd (1993) finds no evidence of discrimination against females in the expenditure data of Taiwan during the early 1990s.

${ }^{4}$ See Parish and Willis (1993), Butcher and Case (1994), Kaestner (1997), Garg and Morduch (1998), Morduch (2000), Steelman, Powell, Werum and Carter (2002) and Lafortune and Lee (2014).

${ }^{5}$ Vogl (2013) estimates the overall impact of a next sister on older sisters' marriage and parental co-residence, using data from South Asia where the son-preferring stopping rule is prevalent. Having a next sister not only increases family size but also increases the firstborn girl's marriage risk. Both $D E$ and $I E$ of a next sister on firstborn outcomes in this context are likely negative.
} 
works because mothers are unable to respond to a firstborn infant's gender by having more babies in such a short window. They find strong evidence of gender imbalance in receiving childcare, which is not masked by the son-preferring fertility-stopping rule.

Our objective is to provide causal estimates of $D E$ and $I E$ of a next brother on the education of firstborn females/males. ${ }^{6}$ We focus on the sibling gender effects on the firstborn, not on children born later, because the presence of any later-born child is endogenous, depending on the gender composition of existing siblings. Under the son-preferring stopping rule, a firstborn son reduces completed family size. Consequently, a comparison of the outcomes of younger sisters with a firstborn brother versus a firstborn sister captures the differences in parental demand for sons and desire for a large family, in addition to the effect of firstborn gender; thus, it is difficult to interpret causally. ${ }^{7}$ We address this issue by focusing on firstborn outcomes.

This study confronts four important challenges. The first is to formulate $D E$ and $I E$ that are valid regardless of whether households follow the son-preferring stopping rule or not. Rather than using the realized sibsize to define $D E$ and $I E$, we use potential sibsize because in counterfactual worlds it is possible to fix/change potential sibsize with a change in sibling gender composition. We decompose the overall impact of sibling gender on human capital accumulation into two separate causal channels: the active reallocation of parental resources along the direction of gender given potential sibsize (i.e. $D E$ ) and the passive effect of sibling gender through changing potential sibsize upon a change in sibling gender composition (i.e. $I E){ }^{8}$ We show that the coefficient of sibling gender in a human capital formation model cannot be interpreted causally, even if consistently estimated, but it is useful in constructing the decomposed effects of sibling gender. Given strong preference for sons, we find evidence that the degree of quality-quantity tradeoffs may vary with sibling gender composition. Thus, an interaction term between sibsize and sibling gender composition is required for unbiased estimation of human capital formation in the presence of gender bias. We show that omission of the interaction term is equivalent to exclusion of the son-preferring fertility-stopping rule, which is strongly rejected by our data.

The second challenge is to address the endogeneity of family size. While a large empirical literature has taken the endogeneity of family size seriously with respect to various outcomes (including child education), ${ }^{9}$ this is less of a recognized issue in studies on the effect of gender composition of siblings. Given that the

\footnotetext{
${ }^{6}$ Our method is a simple modification of a broad literature on quality-quantity tradeoffs (e.g. Black, Devereux and Salvanes, 2005, 2010; Angrist, Lavy and Schlosser, 2010).

${ }^{7}$ The literature on the rivalry effect of male siblings investigates the effect of sex ratios of older siblings (or the total number of sisters/brothers) on child outcomes. Important examples include Parish and Willis (1993), Butcher and Case (1994) and Garg and Morduch (1998). We compare our method with these three studies by using our data and running the same regressions as theirs. We find various results across models (Table A8), and the estimates vary after conditioning on birth order (Table A9).

${ }^{8}$ Oaxaca's decomposition cannot work when the grouping variable (that is, sibsize in this paper) is a mediating variable which affects outcomes (child education) and is affected by the treatment variable (sibling gender composition).

${ }^{9}$ See Black, Devereux and Salvanes (2005, 2010), Li, Zhang and Zhu (2008), Rosenzweig and Zhang (2009) and Angrist, Lavy and Schlosser (2010).
} 
sibling gender effect works in part through its effect on family size, it is important to treat endogenous family size properly. Simply controlling for the realized sibsize in regressions of child outcomes on sibling gender can yield misleading results. Following the previous literature on family size effects on child outcomes, we address the endogeneity issue by exploiting the plausibly exogenous variation in sibsize due to twinning at the second birth, conditional on family background characteristics. Critiques of the twins instrument have noted that the tradeoff between child quality and quantity is understated (or overstated) if parents who have secondborn twins invest more (or less) in the first child than those who have a secondborn singleton, due to an endowment reinforcing (or compensating) motive. Rosenzweig and Zhang (2009) recommend a remedy for this problem by including the initial health conditions of the secondborn children. Because fetal conditions may reflect adult risk of disease or lifestyle, relating to unobserved factors of child outcomes, we prefer not to include child initial conditions in regressions. Nevertheless, we discuss the results from Rosenzweig and Zhang's approach as robustness checks.

The third challenge is to address potential concerns about endogenous child gender, due to potential sex-selective abortion or recall errors. We minimize this possibility by restricting the birth registry data to firstborn children who were born prior to 1985 when abortion was not legal and sex testing technology was not widely available. Using the same data as ours, Lin, Liu and Qian (2014) have noted that the sex ratio at birth for the first two parities remained within the normal range between 1980 and 1992 . The sex ratio started diverging from this after 1986 but only for the third- and higher-parity births. Consistent with their findings, our test statistics show that endogeneity of child gender for the first two births is not a concern in our data.

The fourth challenge is to overcome data limitations. Typically, child outcomes could not be observed directly after infancy, and family size and sibling gender composition could only be observed partially or indirectly. ${ }^{10}$ Using Birth Registry data for all of Taiwan since 1978, we ensure that data on family size and sibling gender composition are complete and accurate, by tracing at least 15 years of fertility history for each mother who first gave birth prior to 1985. By matching Birth Registry records with University Entrance Test records, we can observe each firstborn child's educational outcomes during adolescence, in addition to complete family size and sibling gender composition.

The empirical results of our modified approach indicate that both $D E$ and $I E$ are near zero for firstborn males. In contrast, firstborn females have a negative direct effect and a positive indirect effect, which almost cancel each other out, the result being a near-zero total effect. This finding offers new evidence of gender bias in family settings, evidence that cannot be detected by conventional methods. Conventional

\footnotetext{
${ }^{10}$ One exception is the data from Norway in Black, Devereux and Salvanes (2005, 2010), but decomposed effects of sibling gender composition are not their focus.
} 
measures such as gender gaps have suggested unambiguous female advantages of completing high school and entering university. Ordinary least squares (OLS) estimates also suggest much smaller $D E$ and $I E$ than those constructed from our instrumental variables (IV) estimates.

This study represents the first attempt to formulate and estimate the indirect effect of sibling gender on child outcomes via a change in potential family size. The result pointing to a large and positive indirect effect has important implications for policy. If parents' ability to control their total fertility is restricted (as in the case of the one-child policy in China), the overall impact of sibling gender could be much greater. Although we study a particular economy where son preference is strong, it is exactly in countries where son preference is strongest that we may expect the coexistence of $D E$ and $I E$, driven respectively by gender discrimination among siblings and son-preferring stopping rules.

As a byproduct of our analysis, we find the effects of family size on child education, as well as the direction of omitted variable bias, highly depend on the gender composition of children. OLS overstates family size effects if the next sibling is male and understates them if it is female. This contrast is particularly clear among firstborn females. If the next sibling is also female, parents' utility gain from a larger family is greater. If the next sibling is a brother, the son-preferring stopping rule kicks in and parents' utility gain from a larger family is smaller. The two-stage least squares (2SLS) estimates suggest that a third child in the family would lower firstborn daughters' high school completion rate or university enrollment rate by about one-third if the next sibling is female too. The effect of family size on firstborn males' education is also reduced by a next brother, although the estimates are imprecise and much smaller in magnitude than the effect on firstborn daughters'.

The remainder of this paper is organized as follows. Section 2 introduces our data sets, reports evidence of strong preference for multiple sons and presents descriptive analysis on the relationship between family composition and child education. Section 3 clarifies the definitions of direct and indirect effects and describes our empirical strategies to identify them. Section 4 summarizes the empirical findings, discusses the exogeneity of child gender and the twins instrument, and examines the robustness of our main results. We explore various interpretations for the patterns of effect heterogeneity. Section 5 concludes.

\section{Data and Descriptive Analysis}

Identifying the impact of a change in sibling gender composition on educational achievement requires a large amount of detailed data. The data should contain information about sibling gender composition of completed families and child educational attainment up to the late teens. To fulfill this requirement, we link two Taiwanese national administrative data sets — Birth Registry and University Entrance Test records. 
Our master data file is the Birth Registry of Taiwan since 1978 (the initial year of the digitization of the data). It contains information on each newborn child's birthweight, birth order, birthplace (by district), parents' education levels and everyone's exact birth date. The data also contain everyone's identifier, which allows us to link all children to mothers. We restrict our data to 965,330 mothers whose first child was born when the mother was 18 or older, prior to 4 January 1985 when the Eugenics Protection Law (which lists the cases where pregnant women could legally abort a fetus and thus opens the door to some doctors assisting the abortion of unwanted female fetuses) began to be enforced. ${ }^{11}$ Although prenatal sex testing by ultrasound was introduced in Taiwan during the early 1980s, it was only after 1986 that the technology for sex testing became widely available. Lin, Liu and Qian (2014) show that Taiwanese sex ratios at birth start being unbalanced after 1986, and the unbalanced trends are limited to singletons of third- and higher birth orders. As further discussed in Section 2.2, we show that sex-selective abortion is not a concern in our pre-1985 firstborn data.

Birth Registry has detailed categorical information about parental education. Because the years of education on academic versus vocational tracks are not comparable, we capture the variation in parental education using five indicators: university degree or higher, professional training degree, high school diploma, vocational high school diploma and junior high school diploma. The excluded category — primary school or lower — is the reference group.

To measure the sibling gender composition of completed families, we trace all births of the 965,330 mothers for 15 to 22 years after their first birth, until 1999. No mother in our data had a child in either 1998 or 1999, so the measures of completed family size and sibling gender composition can be considered accurate. Taiwan has no forceful birth-control policy (such as China's one-child policy) promulgated, so son-preferring parents have no incentive to under-report a female birth, as Hull (1990) has raised as a concern for the case of China. Rather, they will keep having children until a boy is born. Thus, our data are not distorted by under-reported female births.

Table 1 summarizes the distribution of the 965,330 families by number of children. To causally link child education to sibling gender composition (depending on the birth order), we focus on the education of 851,044 firstborn singletons from families with two or more children (which account for $88 \%$ of all families). For families with two or more children, the sex ratio of boys to girls for the firstborn is 1.04, but it drops rapidly with the number of children. The sex ratio goes from 1.38 for families with two children to 0.94 or lower for those with three or more children. For groupwise comparisons, we construct an urban indicator for the five special municipalities (Taipei, New Taipei, Kaohsiung, Taichung and Tainan), which are home to $60 \%$

\footnotetext{
${ }^{11}$ We limit our data to fathers no younger than 18 . We exclude observations if the birthday of the second parity is missing, or if the number of multiple births at the second parity exceeds three.
} 
of the total population and each of which has an assembly and budget of its own. In most specifications, we include district fixed effects for firstborn birthplace, and the results show no difference with or without the urban dummy.

\subsection{Education and Characteristics of Firstborn Children}

We acquired education data from the University Entrance Test records of 1996 to 2003 when the firstborn just turned 18. The data include two sets of tests: general tests (conducted in February during the high school senior year) and union entrance tests (conducted in July after high school graduation). These tests offer two distinct channels for university education. Students can apply for university admission using their general test scores and skip the tests in July. If their application results are unsatisfactory, students can forgo early admissions and take the union entrance tests in July after graduation.

We construct an indicator for high school completion using "having taken general tests in February" as a proxy because most graduating seniors take the tests. Typically, the brightest high school graduates attend public universities. During our sample years from 1996 to 2003, tuition fees in public universities were about $14 \%$ of average yearly family income, whereas the cost of attending private university was about $25 \%$.

Although we only observe test scores among admitted students, we observe each test-taker's university admission receipt. Combining this information with Birth Registry, we construct the university admission indicator for each firstborn child being admitted to university at age 18. Our calculation of the rates of high school completion and university attainment excludes vocational high schools and vocational colleges, and uses the firstborn cohort size as denominator. As Table 1 summarizes, $24 \%$ of firstborns from families with two or more children complete (academic) high school and $17 \%$ attain university education, which are the same education levels of the overall firstborn population.

Our treatment group is firstborn children whose next sibling is a brother $($ Boy2nd $=1)$. In the control group, the next sibling is a sister $($ Boy2nd $=0)$. If the second birth results in mixed-gender twins or triplets, then we randomize sibling gender using the fraction of males from the birth — rather than assign the sex ratio or the number of male siblings to Boy2nd - in order to maintain the exclusion restriction condition for the twins instrument and to separate the effect of a next brother from the effect of family size. We set Boy2nd to 1 with probability 0.5 for mixed-gender twins, probability 0.33 for triplets with one male and probability 0.66 for triplets with two males; otherwise, we set it to 0. Overall, 214,846 firstborn females and 222,915 firstborn males are in the treatment group (who have a secondborn brother), while 201,469 firstborn females and 211,814 firstborn males are in the control group (who have a secondborn sister). We discuss our results from balancing checks in the next subsection. 


\subsection{Balancing Tests}

Our empirical strategy requires sibling gender composition at the first two births to be conditionally exogenous. We first note that the sex ratio of boys to girls at birth is 1.044 for firstborns (Table 1) and 1.053-1.066 for their next siblings (Table 2). Both ratios are within the range (1.04-1.08) that demographers consider normal on the basis of historical evidence (Chahnazarian, 1988; Johansson and Nygren, 1991). Since ultrasound (the technology for prenatal testing for child gender) was not available prior to 1980, we further report in Table 2 whether or not the pre- and post-1980 firstborn populations are different. A mean difference test suggests the sex ratio at birth does not differ significantly across cohorts. In fact, the post-1980 cohort is less male-dominated than the pre-1980 cohort. Additionally, the fraction of firstborns who were born in urban areas does not change across cohorts either. However, the mean difference tests show that the post-1980 birth cohort has significantly older and more educated parents. This is because some parents in our firstborn data experienced the expansion of compulsory education from six to nine years during the late 1960s. Compulsory education expansion might have postponed the timing of marriage and childbearing.

Although the presence of sex-selective abortion is neither observable nor testable in the data, we implement balance tests between samples with a secondborn son versus daughter $($ Boy2nd $=1$ versus 0$)$ in samples split by firstborn gender. In Columns (1) and (2) of Table A1, the unconditional mean differences in demographics suggest that secondborn sons are positively associated with older mothers and more educated parents, but this is limited to firstborn females. However, the unconditional mean differences in parental education might just reflect the maternal age effects induced by the son-preferring stopping rules; after having a firstborn daughter, mothers tend to go on having children even at an old age. Indeed, when we include parental education and year of birth and district fixed effects for firstborn birthplace in the regression of Boy2nd, neither maternal age nor parental education can explain variation in the gender of the secondborn. These results can be found in Columns (1) and (2) of Table A2.

Furthermore, we use the birth interval between the first two births to detect sex-selective abortion at the second birth. After having a firstborn daughter, if a male birth is more likely to be selected by son-preferring parents, the birth spacing could be distorted by the time it takes to abort a female fetus. Regressions of the spacing between the first two births on sibling gender composition and family background factors suggest no evidence of sex-selective abortion at the second birth. As Table 3 shows, the coefficient of the interaction between Girl1st and Boy2nd is small (4.0 days) and statistically insignificant ( $\mathrm{SE}=2.8$ days), suggesting no evidence of sex-selective abortion particularly at the second birth. This estimate is similar to the result when we restrict our sample to firstborns for the pre- or post-1980 birth cohorts. Additionally, the coefficient of Girl1st is significantly negative, indicating that after having a firstborn daughter, the next child is born on 
average only 16 days sooner than if the firstborn had been a son. All of these estimates suggest that although parents have strong demand for sons, sex-selective abortion is not a concern in our data if we control for parental education and year of birth, maternal age at the first birth and district-level fixed effects.

\subsection{Demand for Multiple Sons — Son-Preferring Stopping Rules}

Taiwanese have a long tradition of pro-male bias owing to cultural and economic factors. Confucianism - the grounding philosophy in Taiwan, Japan, Korea and imperial China — dictates social statutes and provides rationales for the subordination of women to men, within a strict family hierarchy. According to Confucianism, family line and wealth should be transmitted from father to son, irrespective of ability, except in cases where there is no direct male line. In return, sons and their spouses assume responsibility for taking care of the parents if they are too infirm to work. In contrast, daughters move out of the family household at the time of marriage. These social norms have acted as old-age social security for the elderly for centuries in the form of extended families composed of sons (and their spouses, if married), unmarried daughters, parents and grandparents. Although old-age social security (not based on employment) in Taiwan began in 2008, extended families (even if they do not live together) are still the primary source of support for the elderly. Thus, the demand for old-age social security is more likely to be met by having more sons.

Statistics suggest that a firstborn son reduces family size. As the top panel of Table 4 shows, firstborn males have 0.26 fewer siblings than firstborn females, conditional on observed family backgrounds. This is over $10 \%$ of the average sibsize of all families (2.47). The effect of having a firstborn son on sibsize is greater among families in rural areas, or when the mother or father's education level is less than high school. Because a firstborn son significantly reduces the chances of having a second child, the families with a firstborn son or firstborn daughter who has a certain number of siblings are not comparable because the former group probably has preferences for larger families. Thus, our analysis separates 434,729 firstborn sons from 416,315 firstborn daughters out of the 851,044 families with two or more children.

We report the demand for multiple sons in the middle and bottom panels of Table 4, where we estimate the effect of a change in sibling gender composition on sibsize in the families with one or more children, conditional on observed family backgrounds. Taiwanese families strongly prefer sons to daughters, and multiple sons to mixed-sex composition — unlike American families, who prefer mixed-sex composition, as documented by Angrist and Evans (1998); and the tendency gets stronger if the mother or the father is less educated or if the child was born in a rural area. Model (I) in the middle panel shows that having a son, regardless of the birth order, decreases sibsize by 0.43 . Because the result indicates that birth order is not important in explaining the demand for sons in our data, we further use Model (II) where we focus on the 
impact of sibling gender composition on sibsize, leaving out the factor of birth order. The results suggest that compared with families with two males, those with two females have about 0.53 more children, and those with mixed-sex composition have about 0.10 more. These estimates are extraordinarily large, since they account for $20 \%$ and $4 \%$, respectively, of the average sibsize (2.67).

Several previous studies have suggested that gender bias is stronger in rural areas (e.g. Barcellos, Carvalho and Lleras-Muney, 2014). Columns (4) and (5) of Table 4 show that the son-preferring stopping behaviors are also more evident in rural areas of Taiwan. Family size reduction because of a firstborn son in rural areas is more than $30 \%(=0.288 / 0.218-1)$ higher than the urban counterpart. Additionally, in urban areas, parents who have a boy and a girl in the first two births have 0.07 more children than those who have two boys ( $\mathrm{SE}=0.003)$. This magnitude in rural areas is more than $65 \%(=0.116 / 0.070-1)$ higher than the urban counterpart. While Taiwanese families in both rural and urban areas have strong demand for sons, it is stronger for rural families than for urban families.

The remainder of Table 4 examines heterogeneity in demand for sons by parental education. Columns (6) to (9) show that family size reduction owing to a firstborn son is more than $35 \%(=0.295 / 0.201-1$; 0.296/0.219-1) stronger if the mother or father has no (vocational or academic) high school diploma. Similar to the rural-urban comparison, the difference in the demand for multiple sons by parental education levels is also more evident in higher parities, as the bottom panel of the table shows. It should be noted that since parental education is higher in urban areas than in rural areas, the comparison across subpopulations does not isolate the comparative static of interest.

\section{Empirical Strategy}

Following the literature on gender bias, we assume sibling gender composition is conditionally exogenous. Using the same data, Lin, Liu and Qian (2014) have provided strong evidence supporting this assumption. We reconfirm in Section 2.2 that evidence of sex selection is absent. Since a firstborn son considerably reduces family size, we split the firstborn population by gender throughout our analysis. We study the causal effects of having a next brother on firstborn education, not on the education of children born later, since having any later-born child is a parental choice that can be affected by the gender composition of existing children.

Consider a regression model of the first child's education $(\mathrm{Y})$ on the sex of the next sibling $(D$ or Boy2nd) and parents' fertility choice $(M)$. We define $M$ as parents' decision to have more than two births ( $M=$ Morethan 2 ) since the first-stage $F$ statistic is stronger (see Table A4). For some specifications, we measure parents' fertility choice by number of children $(M=$ Sibsize $)$. For ease of exposition, the first 
child's gender and family background are suppressed, though always included. ${ }^{12}$

$$
Y=\beta_{0}+\beta_{1} D+\beta_{2} M+\beta_{3} D \times M+\epsilon_{D M}
$$

where $D$ is the indicator for a next brother and the Greek letters are coefficients. In particular, $\beta_{2}$ is the family size effect given a next sister and $\beta_{3}$ indicates the reduction in the family size effect due to a next brother (relative to a next sister). The error term $\epsilon_{D M}$ can vary with fertility choice $M$ and sibling gender $D$ in order to allow each firstborn to have idiosyncratic gains from a next brother or a smaller family. ${ }^{13}$

The interaction between sibling gender $D$ and fertility choice $M$ is required for unbiased estimation because the family size effect may depend on the gender composition of existing children. A next brother can reduce the quality-quantity tradeoff (if any) because son-preferring parents might improve the family environment for that son. In addition, younger brother effects may depend on family size too. For example, if parents have had a son but want a larger family anyway, then a next brother might affect the firstborn daughter's education relatively less because the parents have a weaker pro-son bias compared with those who stop fertility after that son. Given these behaviors, we expect $\beta_{3}>0$.

By keeping the realized fertility choice $M$ constant, conventional methods measure the $D E$ of sibling gender as follows, referred to as the "controlled direct effect": $C D E(M) \equiv E[Y \mid M, D=1]-E[Y \mid M, D=$ $0]=\beta_{1}+\beta_{3} E[M]$. However, this method excludes families who follow the son-preferring stopping rules, so the estimation result is doomed to understate the degree of gender bias or sibling rivalry. Because this measure for $D E$ has kept the observed sibsize constant, it leaves no variation in observed sibsize for data analysts to formulate the indirect effect of sibling gender via a change in sibsize.

Rather than keeping the realized sibsize constant, we use potential sibsize in counterfactual worlds to define $D E$ and $I E$ on individual firstborn children. However, the counterfactual outcome given a next sister and the counterfactual outcome given a next brother cannot both be observed for every firstborn child. Under the assumption of randomized child gender, we use the following two properties to proceed: (1) conditional on sibsize, $\epsilon_{1 M}$ and $\epsilon_{0 M}$ have the same distribution; (2) conditional on randomized sibling gender, the conditional mean of potential sibsize is equal to the conditional mean of observed sibsize. Using these two properties, we show in an appendix that the sample analogs of $D E$ and $I E$ can be written in terms

\footnotetext{
${ }^{12}$ In addition to the firstborn's gender, we include the full set of indicators for urban, the subject's age and district of birth, parents' education and years of birth, and mother's age at the first birth. We exclude child initial health (e.g. birthweight or gestational length) from our regressions because those are bad controls, which can be affected by child gender. Additionally, we estimate standard errors conservatively using robust standard errors. Results remain unchanged when the standard errors are calculated by clustering at the birth district level.

${ }^{13}$ Consider a random-coefficient model, $Y=\beta_{0}+\left(\beta_{1}+\rho_{1}\right) D+\left(\beta_{2}+\rho_{2}\right) M+\left(\beta_{3}+\rho_{3}\right) D \times M+\epsilon$, where $\epsilon$ is independent of $D$ and $M, \rho_{1}$ captures parents' utility gain from having a younger son and $\left(\rho_{2}, \rho_{3}\right)$ capture parents' utility gains from family size. Collecting all error terms yields $\epsilon_{D M}=\epsilon+\rho_{1} D+\rho_{2} M+\rho_{3} D \times M$, which is correlated with $M$ but uncorrelated with the random assignment $D$. This model is less restrictive than a constant-coefficient model, and it can help predict the direction of omitted variable bias (see footnote 14).
} 
of the regression coefficients and the conditional means of realized sibsize:

$$
\begin{aligned}
A D E & =\beta_{1}+\beta_{3} E[M \mid D=1] \\
A I E & =\beta_{2}\{E[M \mid D=1]-E[M \mid D=0]\} .
\end{aligned}
$$

The sample analog of the total effect, $A T E$, is the sum of $A D E$ and $A I E$. Notably, omitting the interaction term $\left(\beta_{3}=0\right)$ is observationally equivalent to equating $E[M]$ and $E[M \mid D=1]$, i.e. assuming fertility choice is not son-preferring. Coexistence of the son-preferring stopping rule $(E[M \mid D=1]<E[M \mid D=0])$ and the quality-quantity tradeoff $\left(\beta_{2}<0\right)$ implies $A I E>0$. If child quality is independent of quantity $\left(\beta_{2}=0\right)$, then $A I E=0$.

To construct unbiased and consistent estimates of $A D E$ and $A I E$, unbiased and consistent estimates of $\left(\beta_{1}, \beta_{2}, \beta_{3}\right)$ are needed. However, problems of endogeneity arise because fertility choice $M$ can be correlated with unobserved parental preferences, family background and child characteristics in $\epsilon_{D M}$. To address this, we apply 2SLS using the incidence of twins at the second birth. The second stage is the outcome equation (1). In the first stage, we instrument $M$ with an indicator of whether the second birth is twins $(Z=T$ win2nd) and we instrument the interaction $D \times M$ with an interaction $D \times Z$, as indicated by these two equations: ${ }^{14}$

$$
\begin{array}{r}
M=\alpha_{0}+\alpha_{1} D+\alpha_{2} Z+\alpha_{3} D \times Z+u, \\
D \times M \quad=\gamma_{0}+\gamma_{1} D+\gamma_{2} Z+\gamma_{3} D \times Z+v .
\end{array}
$$

Error terms $u$ and $v$ can be correlated with $\epsilon_{D M}$. Again, we suppress the gender of the firstborn and the same set of covariates as in the outcome equation (1), for ease of exposition. Since the decomposed effects are both linear in regression coefficients, as equations (2) and (3) indicate, we calculate their standard errors using conventional methods (by testing for linear restrictions). ${ }^{15}$

In summary, we study how a secondborn brother affects the outcomes of the firstborn, either directly or indirectly through changing sibsize. We instrument sibsize with whether the second birth is a twin birth.

\footnotetext{
${ }^{14}$ We illustrate how we can predict the direction of omitted variable bias using the random-coefficient model described in footnote 13. If the next sibling is female, parents' utility gain from a larger family would be greater, so $\operatorname{corr}\left(M, \epsilon_{0 M}\right)=$ $\operatorname{corr}\left(M, \epsilon+\rho_{2} M\right)=\rho_{2}>0$. Thus, OLS understates the magnitude of the quality-quantity tradeoff for firstborn outcomes given a next sister. In contrast, if the next sibling is male, then parents' utility gain from a smaller family would be greater, so $\operatorname{corr}\left(M, \epsilon_{1 M}\right)=\rho_{2}+\rho_{3}<0$. Thus, we expect $\rho_{3}<0$ and OLS overstates the magnitude of the tradeoff given a next brother. Thus, the direction of omitted variable bias for the quality-quantity tradeoff depends on the gender composition of existing children. Additionally, omitting the interaction term would augment the error term: $\epsilon_{D M}=\epsilon+\rho_{1} D+\rho_{2} M+\left(\beta_{3}+\rho_{3}\right) D \times M$. Now we have $\operatorname{corr}\left(M, \epsilon_{0 M}\right)=\rho_{2}>0$ and $\operatorname{corr}\left(M, \epsilon_{1 M}\right)=\rho_{2}+\rho_{3}+\beta_{3}$. The direction of the bias still depends on the gender composition of existing children: 2SLS without the interaction still understates the magnitude of the tradeoff given a next sister. However, given a next brother, the direction of bias depends on the relative magnitudes of $\beta_{3}$ and $\rho_{2}+\rho_{3}$.

${ }^{15}$ Most studies on sibling rivalry overlook the problem of endogenous family size. One important exception is Vogl (2013), who addresses the problem by estimating two separate reduced-form regressions of firstborn sisters' outcomes on two twin sisters relative to a singleton sister and on two twin brothers relative to a singleton brother (that is, the combination of $D$ and $M$ by multiplicity). The difference in these reduced-form estimates, divided by the first stage, will provide a Wald statistic for $\beta_{3}$.
} 
Our identification strategy requires that the twins instrument and the sex composition of the first two births are both conditionally exogenous. We present empirical evidence justifying these requirements in Sections 2.2 and 4.5. To allow fertility choice to be son-preferring, our regression model interacts sibsize with sibling gender and it instruments this interaction by interacting the twins instrument with sibling gender in the first stage. Omitting the interaction term would lead to biased results, as the results in Section 4 suggest.

\section{Empirical Results}

Using data from families with at least two children, we estimate the $A D E$ and $A I E$ of having a next brother on the first child's education, measured by high school completion and university attainment. We first present the OLS benchmark to show the relative importance of the included covariates and the interaction term. We implement 2SLS using twins at the second birth as instrument for fertility choice $M$, measured by Morethan2 or Sibsize. The first-stage estimates suggest no concern over weak instruments. The second-stage results show that quality-quantity tradeoffs appear only among firstborn females whose next sibling is also female. The decomposed results suggest that the conventional measures understate the degree of gender bias, primarily because the interaction between sibsize and sibling gender is omitted and the endogeneity problem of fertility choice is overlooked. The magnitude of understatement is markedly large particularly for firstborn females' high school completion. We report empirical evidence supporting our identification assumption that both sibling gender composition and the twins instrument are conditionally exogenous. Finally, we address other specification concerns and discuss the results about effect heterogeneity.

\subsection{OLS Results}

Before presenting the 2SLS results, we report OLS coefficients in the outcome regression (1) using data that will be used for 2 SLS estimation. Table 5 presents two sets of results: one includes family composition variables $(D=$ Boy $2 n d$ and $M=$ Morethan 2$)$ with no controls and the other additionally includes controls. Results in Table A3 using Sibsize as the fertility choice measure show similar patterns. In the shortest regression with sibling gender as the only regressor, the coefficient of Boy2nd in Columns (1) and (7) represents the unconditional mean difference in firstborn education by gender of the next sibling. In longer regressions with controls, the coefficient of Boy2nd in Columns (4) and (10) represents the conditional mean difference. Both conditional and unconditional mean differences are smaller than 0.3 percentage point. In particular, the conditional mean difference is small and positive for firstborn females, while small and negative for firstborn males. This does not imply no gender bias against females because a negative $A D E$ and a positive $A I E$ of similar magnitudes might have canceled each other out. 
After adding Morethan2 into the regressions with controls, the coefficient of Boy2nd is adjusted downward to be (more) negative. This downward adjustment is expected because the correlation between Boy2nd and Morethan2 is strongly negative due to the son-preferring stopping rule. A next brother induces son-preferring parents to have a smaller family and thus enables them to invest more in the first child. To allow the sibsize effect to vary with sibling gender (or the sibling gender effects to vary with sibsize), we further add the interaction between sibsize and sibling gender in the outcome regression. In the models including the interaction, the coefficient of Boy2nd and the coefficient of Morethan2 significantly decrease with inclusion of the control variables (e.g., parents' education). This suggests that omitting parents' education and other family backgrounds may lead to overstatement of the two coefficients. Contrary to what we have expected (as explained in Section 3), the OLS estimated coefficient of the interaction term is negative, seemingly suggesting that firstborn children's outcomes are more hurt by a larger family if the next sibling is male. However, the endogeneity issue of fertility choice is intensified by its interaction with gender composition. The OLS estimates with or without interactions are both biased and difficult to compare/interpret.

\subsection{First-Stage Estimates}

To address endogeneity of family size and its interaction with sibling gender, we instrument Morethan2 using the occurrence of twins at the second birth $($ Twin2nd) and we instrument Morethan2 $\times$ Boy2nd using the interaction Twin2nd $\times$ Boy2nd. Table A4 shows a strong first-stage. The estimates in Columns (2) and (4) of the top panel suggest that a twin birth significantly increases the probability of having more than two births. Additionally, firstborn females have a smaller first-stage estimate than firstborn males because families with a firstborn daughter tend to opt for a larger family anyway, regardless of the occurrence of twins. In particular, when the first two births are both male, the first-stage estimate is largest, at around 60 percentage points $(=0.539+0.067)$, as Column $(4)$ shows. In contrast, when the first two births are both female, the first stage is smallest, at around 32 percentage points, as Column (2) indicates. These estimates are precisely estimated, with standard errors no larger than 0.7 percentage points. In panels (3) and (4), we also report the first-stage estimates for Sibsize and its interaction with Boy2nd. The results suggest a twin birth increases the number of siblings by about $0.6-0.7$ children $(\mathrm{SE} \leq 0.03)$ for various compositions of sibling gender.

The first-stage F-statistic for Morethan2 and its interaction with Boy2nd, calculated in a manner that takes account of multiple endogenous variables (as in Angrist and Pischke (2009, pp. 217-218)), is between 2,046 and 12,866. The same F-statistic for Sibsize and its interaction with Boy2nd is between 488 and 6,300 , markedly lower but still outside the range where bias in 2SLS estimates could be a concern. Because 
the first-stage $F$-statistic for Morethan2 is considerably larger than that for Sibsize, we focus our discussion on the results using Morethan2. ${ }^{16}$

\subsection{Second-Stage Estimates and Quality-Quantity Tradeoffs}

We report the second-stage results for two educational outcomes — high school completion and university attainment - at the top of Tables 6 and 7 respectively. We noted in Section 3 that the coefficient of a next brother (Boy2nd) cannot be interpreted as his direct effect on firstborn outcomes, although it helps estimate the direct rivalry effect (see results in the next subsection). In what follows, we explain why interactions between sibsize and sibling gender are required for unbiased estimation, discuss how family size effects change with gender composition, and relate our findings to the literature on family size effects.

Under the son-preferring fertility-stopping rule, omission of interactions between sibsize and sibling gender is equivalent to assuming sibsize and sibling gender affect the first child's outcomes through two independent channels. This assumption is unrealistic under the stopping rule because parents desired family size may change with the gender composition of existing children. As a result, the magnitude of the quality-quantity tradeoff can vary with sibling gender composition. For example, a next brother (relative to a next sister) may induce son-preferring parents to improve the family environment, such as by increasing the time the mother spends at home (Rose, 2000), increasing the father's labor supply and wages (Lundberg and Rose, 2002) and increasing the probability of parents staying together (Ananat and Michaels, 2008; Dahl and Moretti, 2008). These improvements initially for the younger son may benefit firstborns too. The parents' behavioral adjustments for a younger son suggest a positive coefficient of the interaction between Boy2nd and Morethan2, which can offset some of the quality-quantity tradeoffs (if any).

As Columns (5) and (10) in both tables show, the 2SLS estimated coefficient of the interaction is indeed positive and cancels out a large part of the main effect of family size, given a next brother. Firstborn daughters with a next brother receive almost no family size effect, as suggested by the sum of the family size main effect and the coefficient of the interaction term. In contrast, given a next sister, the family size effect is startlingly strong for firstborn females. If parents go on to have a third child, then firstborn daughters with a next sister face a 10 percentage point reduction in high school completion and a 7 percentage point reduction in university attainment. This accounts for nearly $40 \%$ of the average high school completion rate and the average university enrollment rate. ${ }^{17}$ The pattern of these estimates is robust, irrespective of using Morethan2 or Sibsize as the measure for family size — see Tables 8 and 9. Similar results appear among firstborn sons, although all estimates regarding the effects of family size and interactions are small

\footnotetext{
${ }^{16}$ Reduced-form results can be found in Table A5.

${ }^{17} 0.0955 / 0.246$ or $0.0669 / 0.177$ is approximately $40 \%$.
} 
and insignificant.

To investigate the magnitude of omitted variable bias in estimating the family size effects, we compare the OLS and 2SLS results in Columns (4) and (5) or Columns (9) and (10), both including interactions. ${ }^{18}$ We find that the OLS understates the quality-quantity tradeoff given a next sister, but overstates the tradeoff given a next brother. This pattern of biases is particularly evident among firstborn females. Specifically, for firstborn daughters with a next sister, the OLS estimated impact of a third child in the family is only a 1 percentage point reduction in both high school completion and university attainment. This accounts for less than $13 \%$ of the tradeoff suggested by 2 SLS estimates. ${ }^{19}$ In contrast, for firstborn daughters with a next brother, OLS estimates suggest a third child in the family reduces firstborn daughters' educational attainment by 2 percentage points, significantly greater than the zero effect that the 2SLS estimate would suggest. ${ }^{20}$ The relationship between the direction of bias and the gender composition of existing children is consistent with what we predicted in footnote 14 .

Omitted interaction bias is a special case of omitted variable bias. For the purposes of comparing estimation results using the same set of compliers as in the full model, we interact Twin2nd and Boy2nd in the first stage while omitting the interaction between Morethan2 and Boy2nd in the second stage. The 2SLS results in Columns (3) and (8) suggest that omitting interactions in the second stage leads to understatement of the quality-quantity tradeoffs given a next sister, but overstatement given a next brother. ${ }^{21}$ This is as we predicted earlier in footnote 14 for general directions of omitted variable bias even if interactions are included.

In summary, the second-stage results suggest that under son preference and the son-preferring fertilitystopping rule, the family size effect strongly depends on sibling gender composition particularly among firstborn daughters. Although not the main focus of this paper, this part of the analysis relates to the literature on the effect of family size on child outcomes or parental behaviors, using variation due to twin births or preferences for a specific gender composition. Rosenzweig and Wolpin (1980) were the first to use twins to identify family size effects and Angrist and Evans (1998) were the first to use the gender composition of existing children to identify the family size effects on parents' labor supply. More recently, Black, Devereux and Salvanes (2005) and Angrist, Lavy and Schlosser (2010) find no evidence in data from Norway and Israel that an exogenous increase in the number of younger siblings (induced by twins or variation in sibling gender composition) affects adult outcomes. Black, Devereux and Salvanes (2010) focus on younger Norwegian

\footnotetext{
${ }^{18}$ It is difficult to explain the change in OLS estimates from Column (1) or (6) (without interactions) to Column (4) or (9) (with interactions) because both contain omitted variables correlated with family size.

${ }^{19} 0.0109 / 0.0955$ and $0.0088 / 0.0669$ are no more than $13 \%$.

${ }^{20}$ The OLS estimate here is derived by summing the coefficients of Morethan2 and its interaction with Boy2nd (-0.0109 0.0109 from Table 6$)$ in Column (4). The corresponding 2SLS estimate is derived using data in Column (5) $(-0.0955+0.0960)$.

${ }^{21}$ Example comparisons are $|0.0240|<|0.0955|$ given a next sister and $|0.0240|>|0.0955+0.0960|$ given a next brother.
} 
cohorts and find mixed evidence: no evidence that an exogenous increase in family size induced by gender composition has an impact on IQ scores, but some evidence that an increase in family size induced by twins has a negative impact. Conley and Glauber (2006) and Cáceres-Delpiano (2006) find negative family size effects on attending private school in the United States. However, while the former suggest a negative impact of family size on grade retention, the latter shows no significant impact.

Other empirical work that exploits an exogenous increase in the number of younger siblings has used data from developing countries. Important examples are Li, Zhang and Zhu (2008) and Rosenzweig and Zhang (2009), both using Chinese twins, and Ponczek and Souza (2012) using Brazilian twins. These three studies from developing countries suggest a marked tradeoff between child quality and quantity. Rosenzweig and Wolpin (2000) have noted that in countries such as India where son preference is strong, gender composition might directly affect outcomes due to economies of scale, such as clothes sharing. More generally, gender composition directly affects adult outcomes, including parents' labor supply and earnings and the relationship between them $;^{22}$ thus, child outcomes are also likely affected through channels other than variation in family size. In the following subsection, we show robust evidence of a direct impact of a next brother on high school completion of firstborn daughters and sons in Taiwan. This suggests that in regions such as Taiwan where the son-preferring stopping rule is prevalent, gender composition is not a valid instrument for family size since it violates the exclusion restriction by directly affecting child education.

\subsection{Main Results: Decomposed Effects of Sibling Gender}

The baseline decomposed results appear at the bottom of Tables 6 and 7 , which summarize the sample analogs of the total effect, indirect effect and direct effect of a next brother on the education of firstborn daughters and sons (denoted by $A T E, A I E$ and $A D E$ ). As simple statistics suggest that firstborn females are more likely than firstborn males to complete high school or enroll in university, even with markedly strong demand for sons, the $A T E$ of a next brother on firstborn education also seemingly suggests no gender discrimination; for both firstborn females and firstborn males, the ATE is nearly zero although some are statistically significant.

However, a zero or positive $A T E$ is likely a result of the son-preferring stopping rule being prevalent. A positive indirect effect of a younger brother - via reduced family size - might have masked the direct rivalry effect on his older sibling. Since the magnitude of the $A I E$ has not been revealed before, we first describe in detail how we estimate AIE using the strategy introduced in Section 3. For example, the 2SLS full model in Column (5) of Table 6 shows that $A I E=0.0211$, which is derived by multiplying the effect of Morethan 2 on

\footnotetext{
${ }^{22}$ See Rose (2000) and Lundberg and Rose (2002) using data from India and Dahl and Moretti (2008) and Ananat and Michaels (2008) using data from the United States.
} 
the firstborn daughter's high school completion given a next sister (that is, $\beta_{2}=0.0955$ ) by the effect of a next brother on the probability of having Morethand (that is, $E[M \mid D=1]-E[M \mid D=0]=0.4787-0.6991$ ). Similarly, $A D E=0.0192$ is derived by the 2SLS estimated coefficient on Boy2nd (that is, $\beta_{1}=0.0651$ ) plus the interaction's coefficient $\left(\beta_{3}=0.0960\right)$ being multiplied by the probability of Morethan2 when the secondborn is male $(E[M \mid D=1]=0.4787)$. Since both $A I E$ and $A D E$ estimators are linear in the regression coefficients, we use a simple linear restriction to derive the standard errors.

Additionally, we use an alternative family size measure, Sibsize, to estimate the decomposed effects, as Tables 8 and 9 show. Because the decomposed results are strikingly similar, irrespective of the choice of family size measure, and because the first stage for Morethan2 is stronger than that for Sibsize, our discussion focuses on the 2SLS results using Morethan2.

The 2SLS estimated AIE suggests that through decreasing potential sibsize of firstborn daughters, a next brother indirectly causes a 2 percentage point increase in the probability of completing high school and a 1.5 percentage point increase in the probability of enrolling in university. The results are almost identical using either Morethan2 or Sibsize, as shown in Column (5) of Tables 6 and 8 for high school completion and Tables 7 and 9 for university attainment. The magnitude of $A I E$ is not negligible since it accounts for $9 \%(0.0211 / 0.246)$ of the high school completion rate and $8 \%(0.0148 / 0.177)$ of the university enrollment rate, both precisely estimated. In contrast, the 2SLS estimates of the AIE on firstborn sons' high school completion and university attainment are only 0.2 percentage points, accounting for $1 \%(0.0020 / 0.239$ or $0.0017 / 0.153)$ of the sample mean or less.

The markedly large difference in the magnitude of the $A I E$ between firstborn daughters and sons indicates the presence of gender bias, resulting primarily from two factors. (i) Firstborn daughters bear a much larger family size effect than firstborn sons do, if the next sibling is female. If the next sibling is male, the qualityquantity tradeoffs are nearly zero for firstborn sons and daughters. (ii) While a next brother decreases the probability for firstborn sons of having Morethan2 by only 6 percentage points $(E[M \mid D=1]-E[M \mid D=$ $0]=0.4191-0.4831)$, the reduction is much higher for firstborn daughters, at about 22 percentage points $(0.4787-0.6991)$. This result is not surprising because we now allow families to follow the son-preferring stopping rule in the model by interacting sibsize with sibling gender composition.

The large positive $A I E$ on firstborn daughters almost entirely offsets the direct rivalry effect of male siblings, measured by $A D E$. The 2SLS estimated $A D E$ in Column (5) of Tables 6 and 7 suggests that a next brother directly reduces the probability for firstborn daughters of completing high school by 1.9 percentage points $(\mathrm{SE}=0.0076)$ and of enrolling in university by 1.3 percentage points $(\mathrm{SE}=0.0069)$. Both $A D E$ s account for $7-8 \%(0.0192 / 0.246$ or $0.0125 / 0.177)$ of the sample mean. In contrast, the 2SLS estimated $A D E$ for firstborn sons, reported in Column (10), suggests that a next brother has little impact on firstborn 
sons' high school completion or university attainment. The estimates have standard errors as small as 0.2 percentage points. We note that regardless of firstborn gender, the negative $A D E$ is almost entirely offset by the positive $A I E$, resulting in a nearly zero total effect.

In the previous literature, the direct rivalry effect of male siblings was measured by the coefficient of Boy2nd in regression models without interactions, and sibsize was assumed to be exogenous and independent of the gender composition of older siblings. Our OLS estimated coefficients of Boy2nd in Columns (1) and (6) indicate a nearly zero direct rivalry effect, regardless of firstborn gender. This coefficient is equal to $C D E$ assuming no interaction term. Even if the interaction term is included, as in Columns (4) and (9), the OLS estimated $C D E$ remains small or statistically insignificant. Overall, the OLS estimates show no sign of sibling rivalry, irrespective of whether the interaction is included.

The 2SLS estimated $C D E$ excluding the interaction also considerably understates $A D E$. As Columns (2) and (3) show, without interactions, the 2SLS estimated CDE on firstborn daughters suggests a decrease in high school completion by $0.3-0.6$ percentage points and a decrease in university enrollment by $0.2-0.4$ percentage points. These only capture less than one-third of the 2SLS estimated ADE in Column (5) where the interaction term is included. Similar patterns appear in Columns (7) and (8) for firstborn sons.

In Column (5) of both tables, we can compare the 2SLS estimated $A D E$ and $C D E$ among firstborn females using the same regression model. The former is more than double the latter, and the downward bias of $C D E$ is statistically significant for high school completion but imprecise for university attainment. The key difference between these two measures is that $A D E$ is evaluated at the conditional mean of family size as if every firstborn's next sibling were male. In contrast, $C D E$ is evaluated at the unconditional mean, assuming sibsize does not adjust for the gender composition of existing siblings. The gap between conditional and unconditional family size is larger among firstborn daughters because many parents follow the son-preferring stopping rule. The stronger the demand for sons is, the larger the downward bias of $C D E$ is. A firstborn son lessens parental demand for sons, so the downward bias of $C D E$ is smaller among firstborn sons.

Overall, the decomposed effects of sibling gender are larger on firstborn females than on firstborn males. As the estimates of the full 2SLS model suggest, $A I E$ for firstborn females is nine or ten times $(0.0148 / 0.0017$ or $0.0211 / 0.0020$ ) that for firstborn males, and $A D E$ for firstborn females is at least quadruple that for firstborn males. This reveals a strong gender bias against firstborn females' educational attainment, which cannot be uncovered by conventional measures, such as $A T E$ or $C D E$, or from the coefficient of sibling gender. The decomposition results are robust, regardless of which fertility choice measure (Sibsize or Morethan2) is adopted, as long as we include an interaction term in the 2SLS model. 


\subsection{Testing for Exogeneity of the Twins Instrument}

Conditional exogeneity of the twins instrument has been questioned because twins have lower birthweight. The birth of twin siblings likely has a direct effect on firstborn children beyond just increasing family size. Weaker health conditions of secondborn twins may induce parents to divert family resources from the twins to the firstborn singleton (if parents have efficiency concerns) or the other way around (if parents have inequality aversion). In either case, estimation results regarding the family size effect and the decomposed effects of sibling gender will be biased.

Although conditional exogeneity of the twins instrument is not testable, we examine whether the occurrence of twins can be explained by observed family backgrounds, such as parental age and education, and district fixed effects of the firstborn's birthplace. We begin by testing the significance of the unconditional mean differences in family backgrounds by Twin2nd. As Columns (3) and (4) of Table A1 show, the occurrence of twins appears to increase with parental education, maternal age and the birthplace being urban. Because the correlation between parental education and twinning might result from age effects, a more sensible check for conditional exogeneity is to test the significance of the conditional mean differences. In Table A2, we test whether or not Twin2nd can be explained by parental education, after controlling for the full set of dummies for parental birth years, maternal age and district fixed effects. The large p-value rejects the joint hypothesis that the full set of parental education dummies is important in explaining variation in Twin2nd. Additionally, after controlling for district fixed effects of firstborn birthplace, the coefficient of the urban dummy becomes insignificant. These statistics suggest no evidence that endogeneity of it Twin2nd can be a major concern after controlling for observed family backgrounds. ${ }^{23}$

Rosenzweig and Zhang (2009) recommend controlling for the mean birthweight of secondborn twins to address the issue of twins' endowment deficit. The idea is that by fixing the birthweight of the second birth (in addition to family background), the only channel through which twinning at the second birth can affect the firstborn child's education is through changing the sibsize. However, this approach is not suitable for studies aiming to detect gender bias because boys are heavier than girls at birth on average. Part of the younger brother rivalry effect would be mistaken as a birthweight effect if we included the mean birthweight of the secondborn. Indeed, as Columns (3) and (7) of Table 10 show for firstborn girls, inclusion of the mean birthweight of the second birth considerably decreases the estimated decomposed effects and family size effects by approximately one-third (0.0144/0.0211-1 using AIE for high school completion as an example). Black, Devereux and Salvanes (2010) have noted that conditional exogeneity of Twin2nd might be

\footnotetext{
${ }^{23}$ The first ovulation induction technology was developed in the laboratory during the late 1950s, but it was not until 1993 that the World Health Organization started evaluating the effectiveness of the related technology. Most children in our data were born prior to 1993 and the effectiveness of fertility-inducing drugs was not clear then. Thus, the chance of ovulation-inducing technologies being commercialized or widespread would be very low during our data period.
} 
invalidated by inclusion of initial health conditions (such as birthweight). Birthweight is endogenous since it can be shaped by a wide range of factors, including maternal education, the introduction of social programs, and the interplay of genes and environments (see, e.g., Almond, Chay and Lee (2005) and Currie (2009)). Thus, our baseline results exclude the birthweight of twins from the analysis.

\subsection{Other Specification Issues}

We investigate more specification issues in Table 10 using data from firstborn daughters. Estimates for firstborn sons in Table A7 have similar patterns although much smaller in magnitude and mostly insignificant.

Similar to the problem with birthweight, gestational length is another initial health condition that is arguably endogenous, being partly dependent on the child's gender. In our data, boys at the second birth have 0.048 weeks shorter gestational period $(\mathrm{SE}=0.003)$ and are 104 grams heavier at birth $(\mathrm{SE}=1.007)$, on average, than their female counterparts. Both differences are significant at the $1 \%$ level. Firstly, to address the problem that Boy2nd affects birthweight, we calculate the birthweight percentile of the second birth given the child's gender, and control for the intrafamily mean of the secondborn birthweight percentile. Columns (2) and (6) of Table 10 show that sibling birthweight percentile is positively correlated with firstborn education. Additionally, sibling birthweight percentile is negatively correlated with family size, as Column (3) of Table A6 indicates. Given that sibling birthweight percentile is positively correlated with firstborn outcomes and negatively correlated with Morethan2, it is to be expected that the family size effect and the decomposed effects both decrease in magnitude when we include sibling birthweight percentile. ${ }^{24}$

In contrast, although gestational periods are slightly shorter for boys than for girls, gestational length has no explanatory power for firstborn education, as Columns (3) and (7) of Table 10 show. Consequently, inclusion of gestational periods has almost no impact on our baseline results (see Columns (1) and (5)).

Spacing between the first two births is potentially a parental choice variable (depending on firstborn gender) because birth spacing decreases significantly with the presence of a firstborn daughter. If the first child is a girl, son-preferring parents tend to rush to try another birth. As Table 3 shows, the main effect of Girl1st on birth spacing is significantly negative, between -10 and -17 days ( $\mathrm{SE}=2-4$ days) . This suggests that birth spacing is endogenous, depending on the gender composition of existing children. Although the coefficient of birth spacing in Columns (4) and (8) of Table 10 is virtually zero, the tight correlation between birth spacing and firstborn gender might make our results difficult to interpret. Thus, we prefer the baseline results to exclude birth spacing although this might have overstated the magnitude of ADE. Nevertheless,

\footnotetext{
${ }^{24}$ The estimated coefficients $\left(\beta_{1}, \beta_{2}, \beta_{3}\right)$ in Columns (2) and (6) of Tables 10 and A7 almost remain unchanged if we replace sibling birthweight percentile with sibling birthweight. This suggests that the downward adjustments in both columns result mostly from the negative correlation between sibling birthweight and family size, not from the association between sibling birthweight and Boy2nd.
} 
when birth spacing is included, our results remain almost unchanged, as shown in Columns (4) and (8) of Table 10 for firstborn females and Table A7 for firstborn males.

This verifies the robustness of our baseline results.

\subsection{Hetergeneity in Younger Brother Effects on Education}

A comparison of the decomposed effects of a next brother on firstborn children from different family backgrounds might shed light on the mechanisms behind our main result.

The top panel of Table 11 first makes a comparison by paternal education for firstborn daughters and sons. Firstborn daughters' high school completion and university attainment are more affected — both directly and indirectly - by a next brother in families with a more educated father. If the father has a high school diploma or more, the direct rivalry effect of a next brother is negative 9 percentage points, which is entirely offset by the strong indirect effect. Both magnitudes are considerably large since they account for around one-third of the sample mean. In contrast, if the father has no high school diploma, then the decomposed effects on firstborn daughters' education are much smaller and insignificant. On firstborn sons' education, the differences by father's education in the younger brother effects are much smaller than for their female counterparts. Similar patterns appear in the comparisons by maternal education and by birthplace, as shown in the second and third panels of Table 11. However, we lose precision for a clear contrast, and the difference between urban and rural areas in the decomposed effects appears only for firstborn daughters' university attainment, not for their high school completion.

The evidence that more educated fathers (or fathers in urban areas) have stronger gender bias against firstborn daughters' education is seemingly contrary to their weaker demand for sons (see Table 4). However, these two results are consistent with Goodkind's (1996) hypothesis, concerning the possible reduction in postnatal discrimination following prenatal sex selection. ${ }^{25}$ In our context, although prenatal sex selection is minimal in our data period (as discussed in Section 2), pro-male bias in fertility choice is manifested by the prevalence of son-preferring fertility-stopping rules. Columns (1) to (4) in the top panel of Table 11 suggest that a more educated father's strong bias against firstborn daughters' education may represent the substitution of his relatively weak son-preferring fertility choice for stronger discrimination in daughters' education investment in the future. The son-preferring stopping rule that passively discriminates against the birth of a daughter may involve reduced discrimination against daughters' education later in life.

It is noteworthy that the substitution of the pro-male bias in fertility for the pro-male bias in parental investment can be driven by credit constraints or cultural factors, or both. Since parental education and

\footnotetext{
${ }^{25}$ Lin, Liu and Qian (2014) have noted that increased access to sex-selective abortion in Taiwan increased the fraction of males born and reduced the relative postnatal mortality rates of girls.
} 
residential areas are associated with family income and taste for education, the comparison across groups does not distinguish one driver from the other.

\section{Conclusion}

Gender bias in family settings is often masked by the practice of son-preferring fertility-stopping rules, particularly in regions where gender bias is strongest. Through stopping fertility after a son, the indirect effect of a younger brother is positive if child outcomes would have been hurt more by a larger family size potentially induced by a younger sister. As a typical result, the younger brother effect on child outcomes appears too small, or the younger sister effect appears too large. Importantly, fertility choice is determined not only by the gender composition of existing children, but also by the parents' unobserved desire for a large or small family, which affects family size and child outcomes simultaneously. Since parents' preference for family size also changes with gender composition, unbiased estimation of younger brother effects and family size effects requires a flexible setup, such as inclusion of interactions between family size and sibling gender composition in IV models. Using this approach, we illustrate a decomposition method to estimate the relative importance of the direct and indirect effects in an integrated framework.

Our decomposed results show that the positive indirect effect almost entirely offsets the negative direct rivalry effect on firstborn girls' high school completion and university attainment, leading to a nearly zero total effect. In contrast, neither the direct nor the indirect effect of a younger brother is important in explaining firstborn sons' education outcomes. The results are robust, irrespective of which measurement choice for family size is adopted and whether or not birth spacing and/or pregnancy duration is included. We further find that gender bias is prone to appear in urban families with more educated parents, which are exactly the subsamples with weaker demand for sons. Pro-male biased fertility choice and pro-male biased parental investment are likely substitutes. One important interpretation of our results is that the overall impact of sibling gender could be much greater if parents are restricted in their ability to control their total fertility (as in the case of the one-child policy in China). While we study a particular economy where son preference is strong, it is in regions where son preference is the strongest that we may expect the coexistence of a negative direct effect and a positive indirect effect, driven respectively by gender discrimination among children and the son-preferring stopping rule.

While family size has been taken as an exogenous control in the literature on sibling rivalry and gender bias, we address the endogeneity issues of family size particularly in the context of the son-preferring stopping rule. Since parents' desire for a smaller family is aroused by the presence of a younger son, the negative correlation between that desire and family size leads to overstatement of the quality-quantity tradeoff (if 
any). By the same token, since parents' desire for a larger family is aroused by the presence of a younger daughter, the positive correlation between that desire and family size leads to understatement. The direction of omitted variable bias changes with sibling gender because of the son-preferring stopping rule. We find only firstborn females whose next sibling is also female have their educational outcomes hurt by adding another child to the family. For the other gender compositions, the estimated effect of family size is smaller and imprecise.

Our findings on family size effects are related to the quality-quantity tradeoff literature that uses sibling sex composition as an instrument for family size (Angrist and Evans, 1998; Black, Devereux and Salvanes, 2005, 2010; Conley and Glauber, 2006; Cáceres-Delpiano, 2006; Angrist, Lavy and Schlosser, 2010). Most of these studies use data from countries where gender bias within the family is arguably small and the demand for sons is rare. It is likely that the direct effect of sibling gender on child outcomes is negligible (e.g. Huber, 2015 ) and that the indirect effect via reduced family size is zero (assuming families do not follow the son-preferring stopping rule). However, for data from countries where gender bias is known, our empirical findings imply that the gender of the firstborn (or the gender composition of children in general) cannot be used as an instrument for fertility since it affects child outcomes directly and violates exclusion restrictions.

As with any study, this paper has some limitations. First, our empirical strategy is only valid when the secondborn's gender is random. However, the randomness of the secondborn's gender may not hold in other regions or for younger cohorts where sex-selective abortions are practiced, as has been shown to be the case in India and China. Second, using the twins instrument, we find the proportion of compliers (i.e., those whose parents would respond to a change in the twins instrument) is $50-60 \%$ of the firstborn population. Given that $88 \%$ of our sample have three or fewer children, the proportion of compliers in some developing countries is likely lower due to stronger demand for children.

Nevertheless, the estimated magnitude of intrafamily gender bias is important for policy. Unlike the previous evidence of gender bias mostly focusing on infant females, our results show that intrafamily gender bias has a sizable negative impact on firstborn female adolescents' education, although it is mostly indirectly offset by parents' fertility-stopping rules. As China recently started to relax the one-child policy and bring in the two-child policy, our results predict that even though intrafamily gender bias against females is likely to continue, some will be offset by the indirect benefits created by allowing couples to freely choose their desired number of children (although only up to the second parity). 


\section{References}

Almond, Douglas, Kenneth Y. Chay and Davis S. Lee. 2005. "The Costs of Low Birth Weight," Quarterly Journal of Economics 120(3): 1031-1083.

Ananat, Elizabeth O. and Guy Michaels. 2008. "The Effect of Marital Breakup on the Income Distribution of Women with Children," Journal of Human Resources 43(3): 611-629.

Angrist, Joshua D. and William N. Evans. 1998. "Children and Their Parents' Labor Supply: Evidence from Exogenous Variations in Family Size," American Economic Review 88(3): 450-477.

Angrist, Joshua D., Victor Lavy and Analia Schlosser. 2010. "Multiple Experiments for the Causal Link between the Quantity and Quality of Children," Journal of Labor Economics 28(4): 773-823.

Barcellos, Silvia H., Leandro S. Carvalho and Adriana Lleras-Muney. 2014. "Child Gender and Parental Investments in India: Are Boys and Girls Treated Differently?" American Economic Journal: Applied Economics 6(1): 157-189.

Barclay, George W. 1954. A Report on Taiwan's Population. Princeton, NJ: Office of Population Research, Princeton University.

Basu, Alaka. M. 1989. "Is Discrimination in Food Really Necessary for Explaining Sex Differentials in Childhood Mortality?" Population Studies 43(2): 193-210.

Black, Sandra E., Paul J. Devereux and Kjell G. Salvanes. 2005. "The More the Merrier? The Effect of Family Size and Birth Order on Children's Education," Quarterly Journal of Economics 120(2): $669-700$.

Black, Sandra E., Paul J. Devereux and Kjell G. Salvanes. 2010. "Small Family, Smart Family? Family Size and the IQ Scores of Young Men," Journal of Human Resources 45(1): 33-58.

Borooah, Vani K. 2004. "Gender Bias among Children in India in Their Diet and Immunisation against Disease," Social Science ES Medicine. 58(9):1719-1731.

Butcher, Kristin F. and Anne Case. 1994. "The Effect of Sibling Sex Composition on Women's Education and Earnings," Quarterly Journal of Economics 109(3): 531-563.

Cáceres-Delpiano, Julio. 2006. "The Impacts of Family Size on Investment in Child Quality," Journal of Human Resources 41(4): 738-754.

Chahnazarian, Anouch. 1988. "Determinants of the Sex Ratio at Birth: Review of Recent Literature," Social Biology 35(3-4): 214-35. 
Chen, Lincoln C., Emdadul Huq and Stan D'Souza. 1981. "Sex Bias in the Family Allocation of Food and Health Care in Rural Bangladesh," Population and Development Review. 17(1):55-70.

Chen, Stacey H., Yen-Chien Chen and Jin-Tan Liu. 2014. "The Impact of Family Composition on Educational Achievement," National Bureau of Economic Research (NBER), Working Paper 20443.

Conley, Dalton and Rebecca Glauber. 2006. "Parental Educational Investment and Children's Academic Risk: Estimates of the Impact of Sibship Size and Birth Order from Exogenous Variation in Fertility," Journal of Human Resources 41(4): 722-737.

Currie, Janet. 2009. "Healthy, Wealthy, and Wise: Socioeconomic Status, Poor Health in Childhood, and Human Capital Development," Journal of Economic Literature 47(1): 87-122.

Dahl, Gordon and Enrico Moretti. 2008. "The Demand for Sons: Evidence from Divorce, Fertility and Shotgun Marriage," Review of Economic Studies 75(4): 1085-1120.

Deaton, Angus. 1997. The Analysis of Household Surveys: A Microeconometric Approach to Development Policy, Baltimore, MD: Johns Hopkins University Press.

Deaton, Angus. 2003. "Health, Inequality, and Economic Development," Journal of Economic Literature 41(1): 113-158.

Duflo, Esther. 2005. "Gender Equality in Development," Bureau for Research in Economic Analysis of Development (BREAD), Policy Paper 011.

Filmer, Deon, Jed Friedman and Norbert Schady. 2009. "Development, Modernization, and Childbearing: The Role of Family Sex Composition," World Bank Economic Review 23(3): 371-398.

Ganatra, Bela R., and Hirve, Siddhi S. 1994. "Male Bias in Health Care Utilization for Under Fives in a Rural Community in Western India," Bulletin of the World Health Organization 72(1):101-104.

Garg, Ashish and Jonathan Morduch. 1998. "Sibling Rivalry and the Gender Gap: Evidence from Child Health Outcomes in Ghana," Journal of Population Economics 11(4): 471-493.

Goodkind, Daniel. 1996. "On Substituting Sex Preference Strategies in East Asia: Does Prenatal Sex Selection Reduce Postnatal Discrimination?" Population and Development Review 22(1): 111-125.

Greenhalgh, Susan. 1985. "Is Inequality Demographically Induced? The Family Cycle and the Distribution of Income in Taiwan," American Anthropologist 87(3): 571-594.

Huber, Martin. 2015. "Testing the Validity of the Sibling Sex Ratio Instrument," Labour 29(1): 1-14.

Hull, Terence H. 1990. "Recent Trends in Sex Ratios at Birth in China," Population and Development Review 16(1): 63-83. 
Jayachandran, Seema and Ilyana Kuziemko. 2011. "Why Do Mothers Breastfeed Girls Less than Boys? Evidence and Implications for Child Health in India," Quarterly Journal of Economics 126(3): 14851538.

Jensen, Robert. 2005. "Equal Treatment, Unequal Outcomes? Generating Sex Inequality through Fertility Behavior," mimeo.

Johansson, Sten and Ola Nygren. 1991. "The Missing Girls of China: A New Demographic Account," Population and Development Review 17(1): 35-51.

Kaestner, Robert. 1997. "Are Brothers Really Better? Sibling Gender Composition and Educational Achievement Revisited," Journal of Human Resources 32(2): 250-284.

Lafortune, Jeanne and Soohyung Lee. 2014. "All for One? Family Size and Children's Educational Distribution under Credit Constraints," American Economic Review: Papers 83 Proceedings 104(5): 365-369.

Li, Hongbin, Junsen Zhang and Yi Zhu. 2008. "The Quantity-Quality Tradeoff of Children in a Developing Country: Identification Using Chinese Twins," Demography 45(1): 223-243.

Lin, Ming-Jen, Jin-Tan Liu and Nancy Qian. 2014. "More Missing Women, Fewer Dying Girls: The Impact of Sex Selective Abortion on Sex at Birth and Relative Female Mortality in Taiwan," Journal of the European Economic Association 12(4): 899-926.

Lundberg, Shelly and Elaina Rose. 2002. "The Effects of Sons and Daughters on Men's Labor Supply and Wages," Review of Economics and Statistics 84(2): 251-268.

Morduch, Jonathan. 2000. "Sibling Rivalry in Africa," American Economic Review 90(2): 405-409.

Parish, William and Robert Willis. 1993. "Daughters, Education and Family Budgets: Taiwan Experiences," Journal of Human Resources 28(4): 863-898.

Ponczek, Vladimir, and Andre Portela Souza. (2012) "New evidence of the causal effect of family size on child quality in a developing country," Journal of Human Resources 47(1): 64-106.

Rose, Elaina. 2000. "Gender Bias, Credit Constraints and Time Allocation in Rural India," Economic Journal 110(465): 738-758.

Rosenblum, Daniel. 2013. "The Effect of Fertility Decisions on Excess Female Mortality in India," Journal of Population Economics 26(1): 147-180.

Rosenzweig, Mark R. and Kenneth I. Wolpin. 1980. "Testing the Quantity-Quality Fertility Model: The Use of Twins as a Natural Experiment," Econometrica 48(1): 227-240. 
Rosenzweig, Mark R. and Kenneth I. Wolpin. 2000. "Natural 'Natural Experiments' in Economics," Journal of Economic Literature 38(4): 827-874.

Rosenzweig, Mark R. and Junsen Zhang. 2009. "Do Population Control Policies Induce More Human Capital Investment? Twins, Birth Weight and China's 'One-Child' Policy," Review of Economic Studies 76(3): 1149-1174.

Rudd, Jeremy B. 1993. "Boy-Girl Discrimination in Taiwan: Evidence from Expenditure Data," Research Program in Development Studies, Princeton University.

Sen, Amartya. 1990. "More than 100 Million Women Are Missing," The New York Review of Books 37(20), December 20 .

Singh, Ashish. 2012. "Gender Based Within-Household Inequality in Childhood Immunization in India: Changes over Time and across Regions," PLOS One 7(4): e35045. doi:10.1371/journal.pone.0035045. Steelman, Lala Carr, Brian Powell, Regina Werum and Scott Carter. 2002. "Reconsidering the Effects of Sibling Configuration: Recent Advances and Challenges," Annual Review of Sociology 28: 243-269.

VanderWeele, Tyler J. 2013. "A Three-Way Decomposition of a Total Effect into Direct, Indirect and Interactive Effects," Epidemiology 24(2): 224-232.

VanderWeele, Tyler J. 2014. "A Unification of Mediation and Interaction: A 4-Way Decomposition," Epidemiology 25(5): 749-761.

Vogl, Tom S. 2013. "Marriage Institutions and Sibling Competition: Evidence from South Asia," Quarterly Journal of Economics 128(3): 1017-1072.

Waldron, Ingrid. 1983. "Sex Differences in Human Mortality: The Role of Genetic Factors," Social Science and Medicine 17(6): 321-333.

Yamaguchi, Kazuo. 1989. "A Formal Theory for Male-Preferring Stopping Rules of Childbearing: Sex Differences in Birth Order and the Number of Siblings," Demography 26(3): 451-465. 


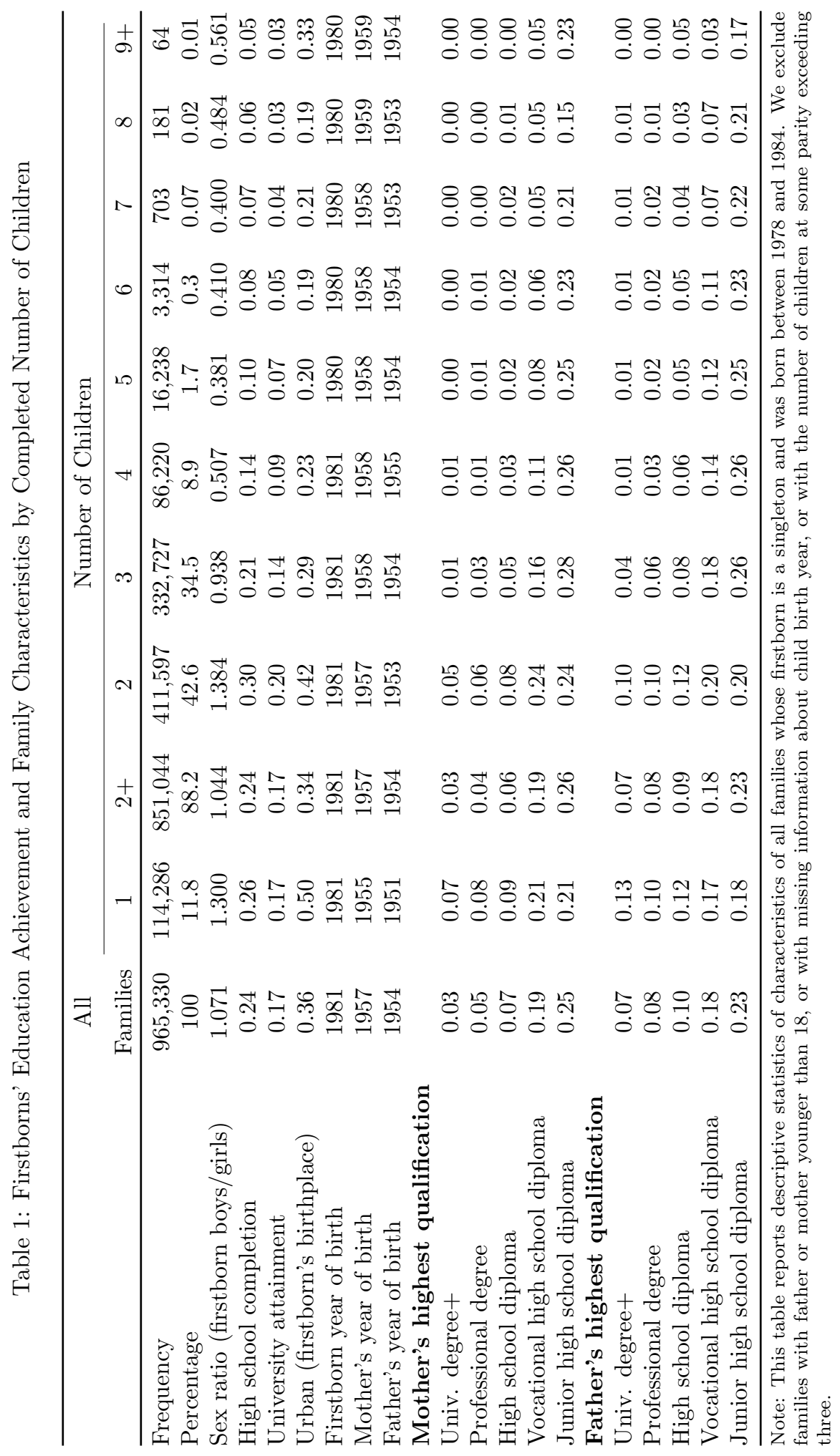




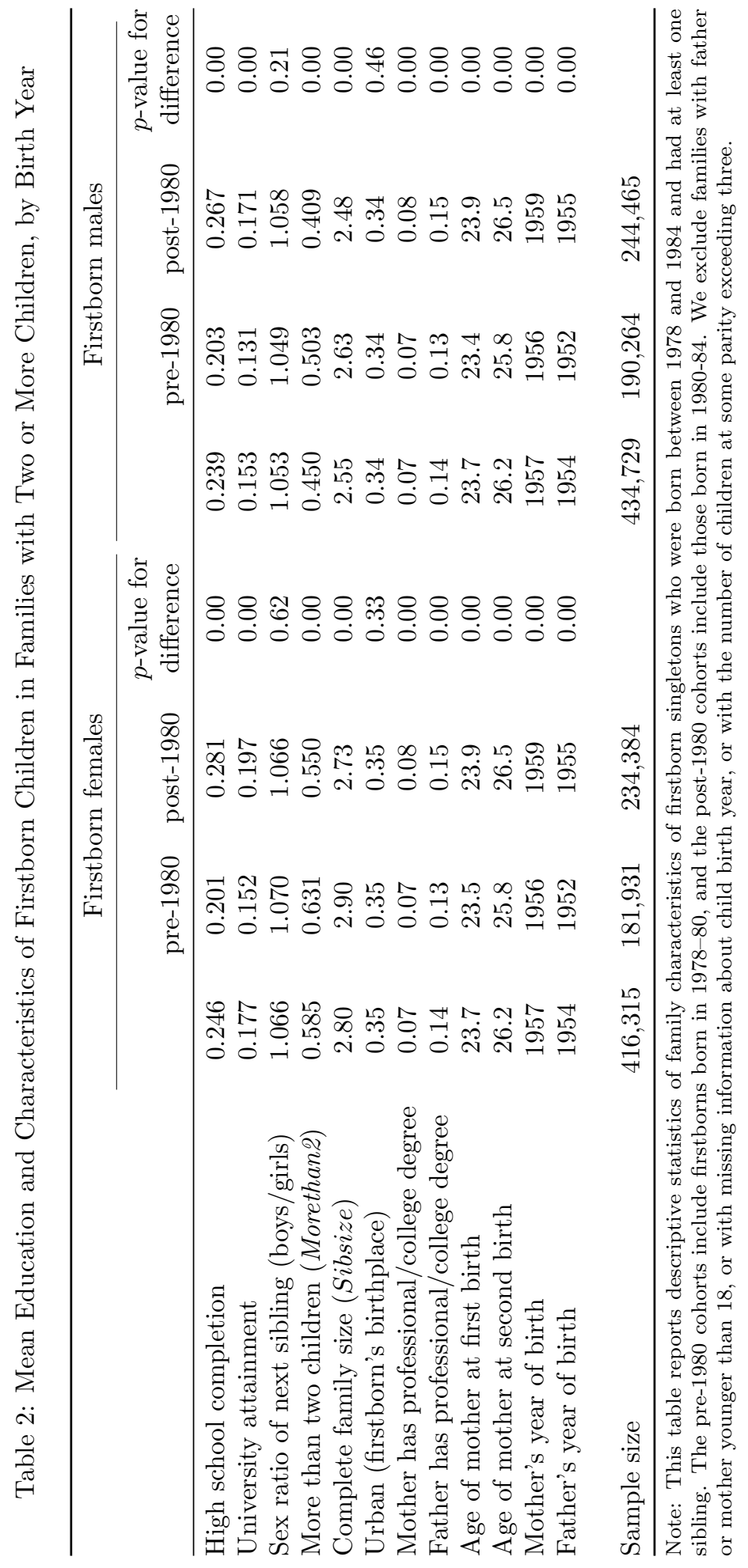


Table 3: Regressions of Birth Spacing (Measured in Days) between the First Two Births

\begin{tabular}{|c|c|c|c|c|}
\hline \multirow[b]{3}{*}{$\begin{array}{l}\text { Dependent variable } \\
=\text { Spacing in days }\end{array}$} & \multicolumn{4}{|c|}{ First child born in } \\
\hline & \multirow{2}{*}{$\begin{array}{c}1978-84 \\
\text { (1) }\end{array}$} & \multirow{2}{*}{$\begin{array}{c}\text { pre- } 1980 \\
\text { (2) }\end{array}$} & \multicolumn{2}{|c|}{ post-1980 } \\
\hline & & & $(3)$ & $\begin{array}{c}\text { next sibling } \\
\text { born by } 1985 \\
\text { (4) }\end{array}$ \\
\hline Girl1st $\times$ Boy2nd & $\begin{array}{c}3.97 \\
(2.81)\end{array}$ & $\begin{array}{c}4.23 \\
(3.42)\end{array}$ & $\begin{array}{c}3.80 \\
(4.88)\end{array}$ & $\begin{array}{l}-3.28 \\
(3.01)\end{array}$ \\
\hline Girl1st & $\begin{array}{l}-15.51 \\
(2.04)\end{array}$ & $\begin{array}{l}-16.61 \\
(2.48)\end{array}$ & $\begin{array}{l}-13.17 \\
(3.55)\end{array}$ & $\begin{array}{l}-9.52 \\
(2.16)\end{array}$ \\
\hline Boy2nd & $\begin{array}{l}-8.13 \\
(1.98)\end{array}$ & $\begin{array}{l}-7.92 \\
(2.42)\end{array}$ & $\begin{array}{l}-8.29 \\
(3.42)\end{array}$ & $\begin{array}{l}1.32 \\
(2.11)\end{array}$ \\
\hline $\begin{array}{l}\text { Adjusted R-squared } \\
\text { Sample size }\end{array}$ & $\begin{array}{c}0.06 \\
850,198\end{array}$ & $\begin{array}{c}0.06 \\
598,777\end{array}$ & $\begin{array}{c}0.05 \\
251,421\end{array}$ & $\begin{array}{c}0.07 \\
241,033\end{array}$ \\
\hline
\end{tabular}

Note: This table reports the OLS estimated coefficients for a regression of birth spacing between the first two births on their sex composition. We use the same sample as the regressions in Tables 5 to 9 , except for 811 families whose secondborn children have missing or erroneous birthday information. We restrict the sample in Column (3) to those whose first child was born from 1980 onwards and the sample in Column (4) to those whose first child was born from 1980 onwards with the second birth prior to 1985. Additional covariates include indicators for urban, parental education and year of birth, mother's age at first birth, and the logarithm of taxable income per capita in the district of birth. Robust standard errors are reported in (.). 


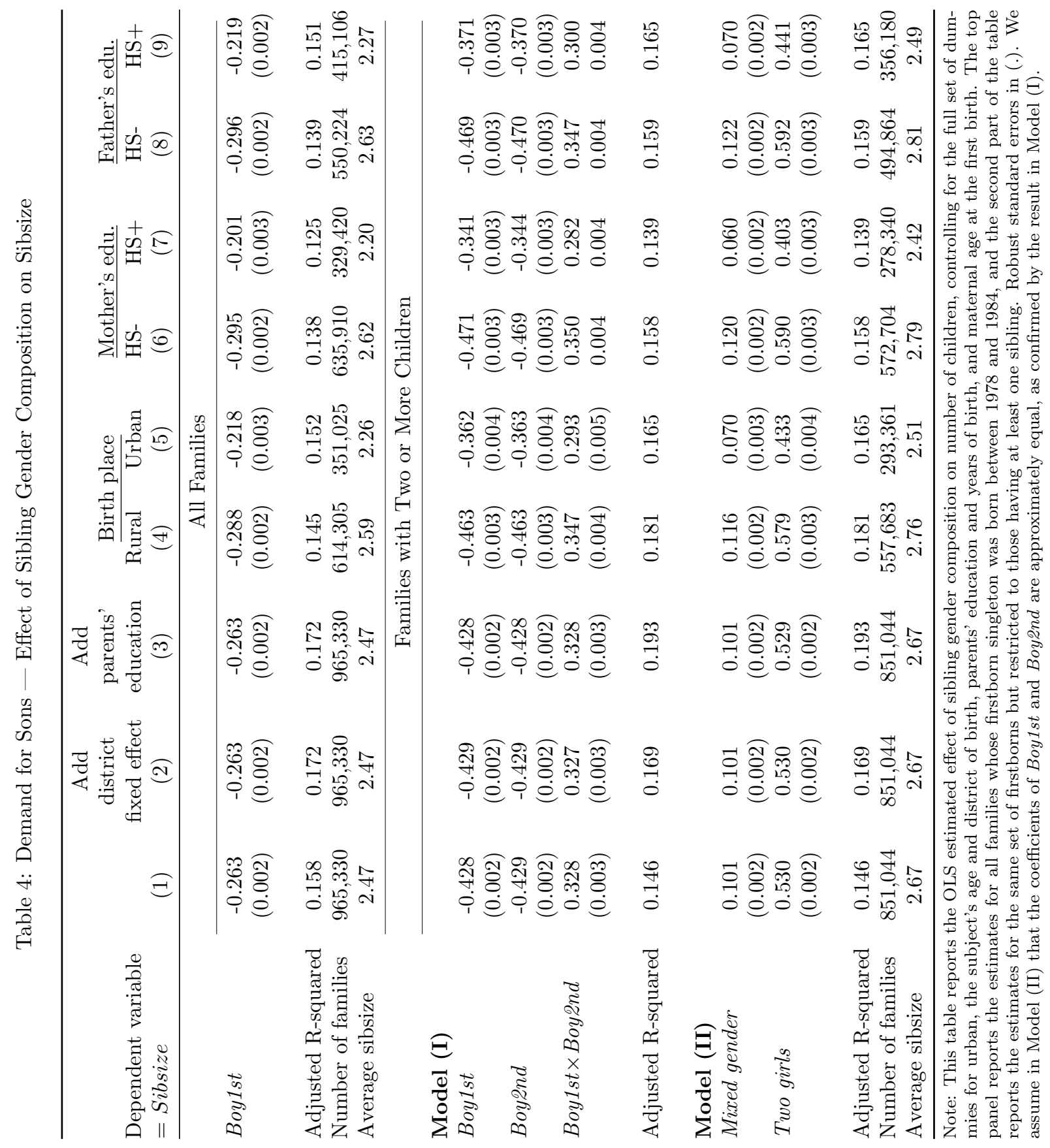




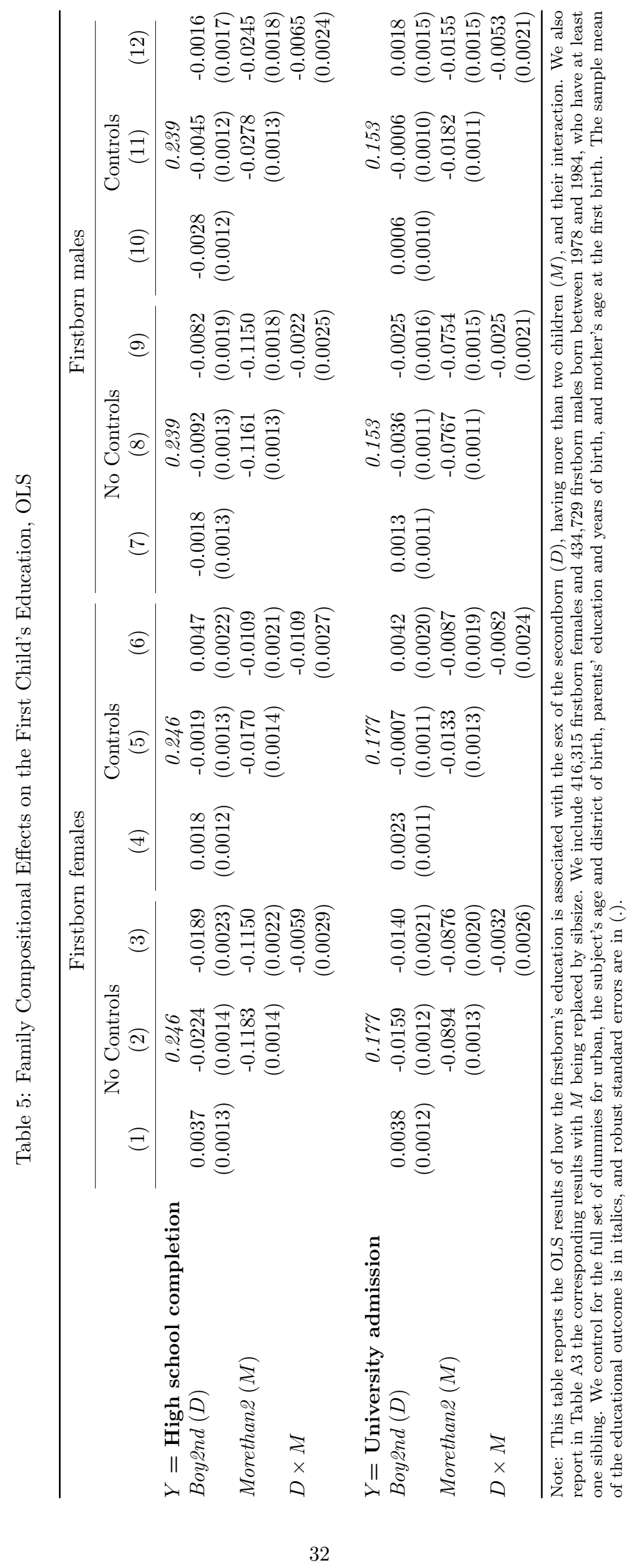




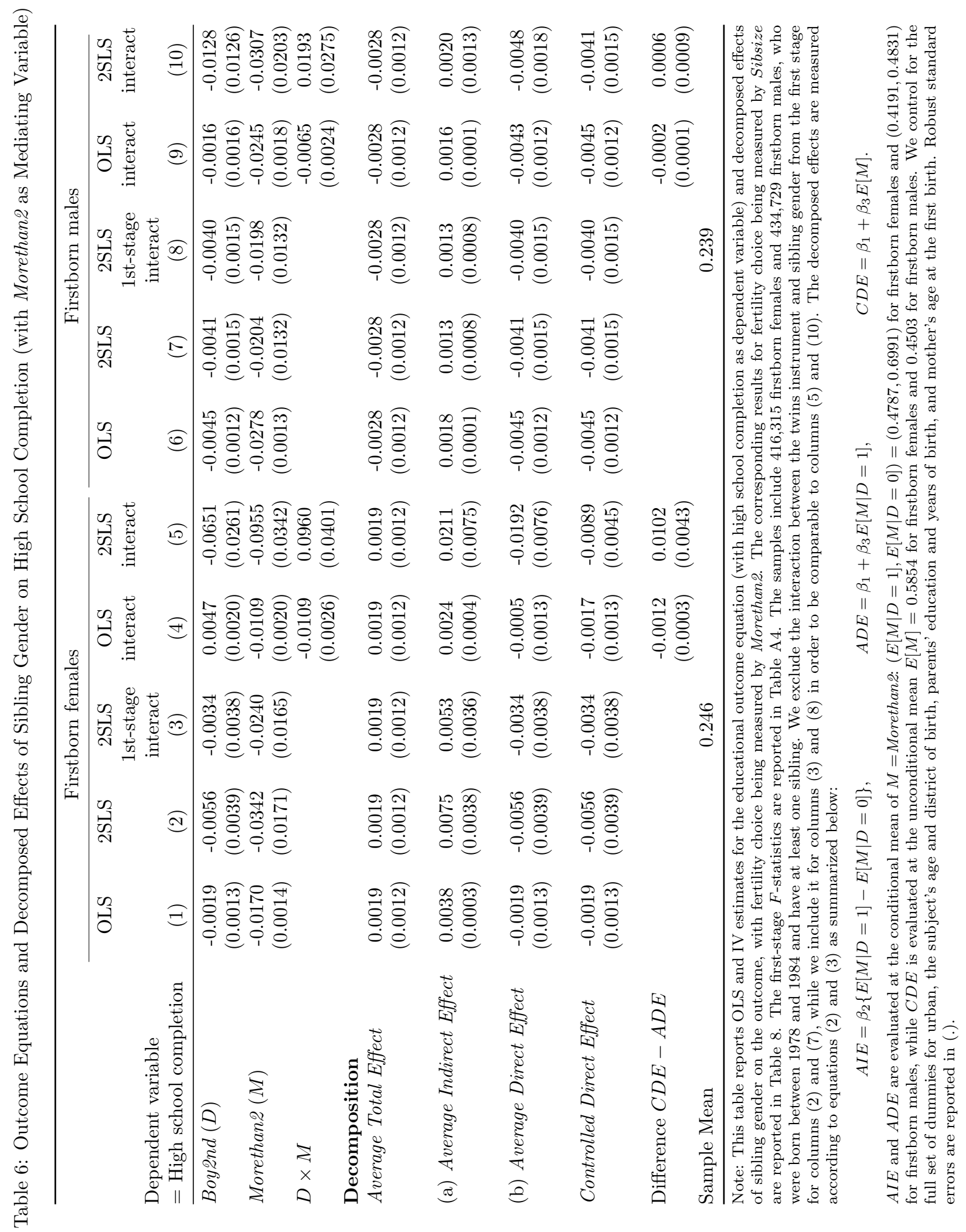




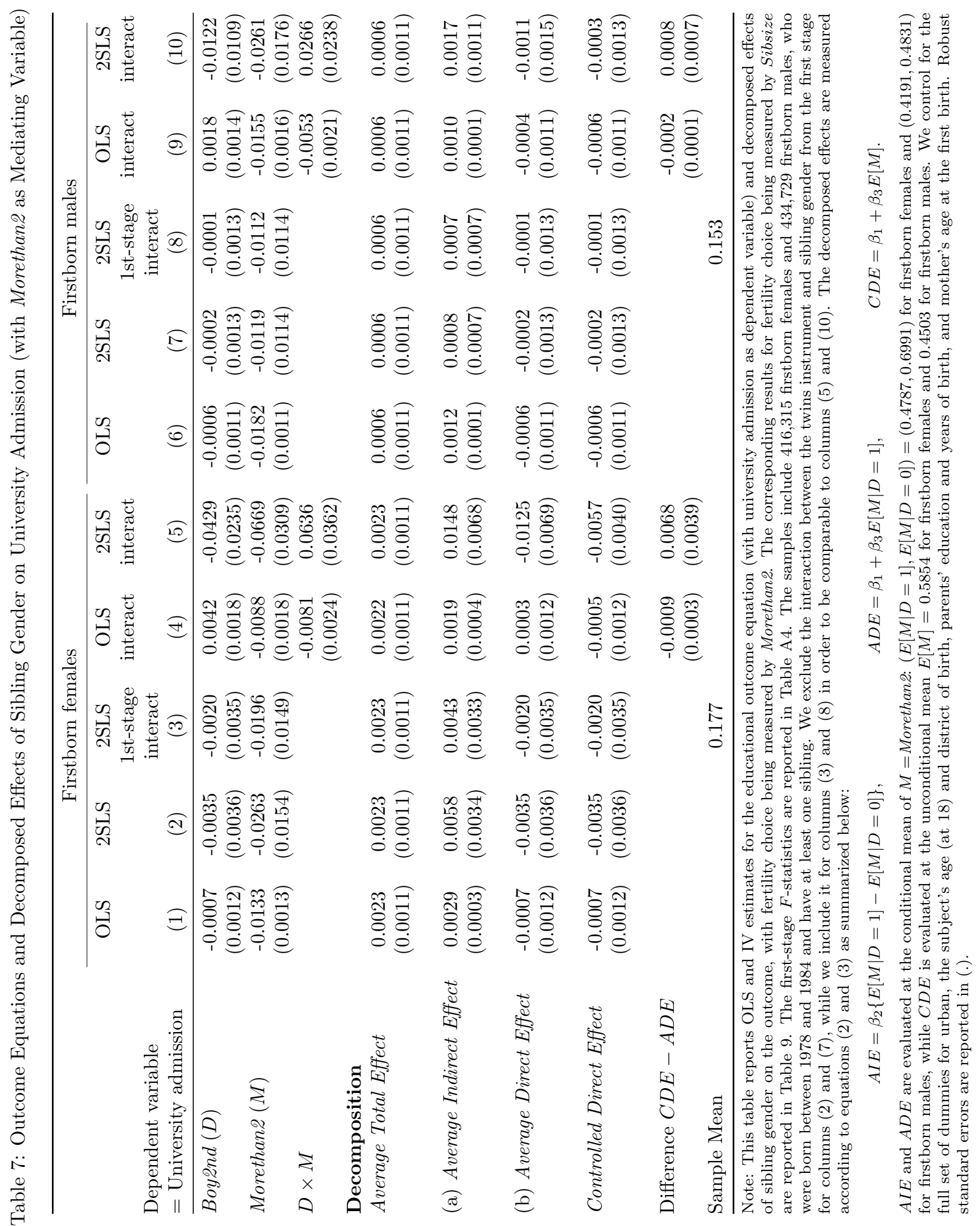




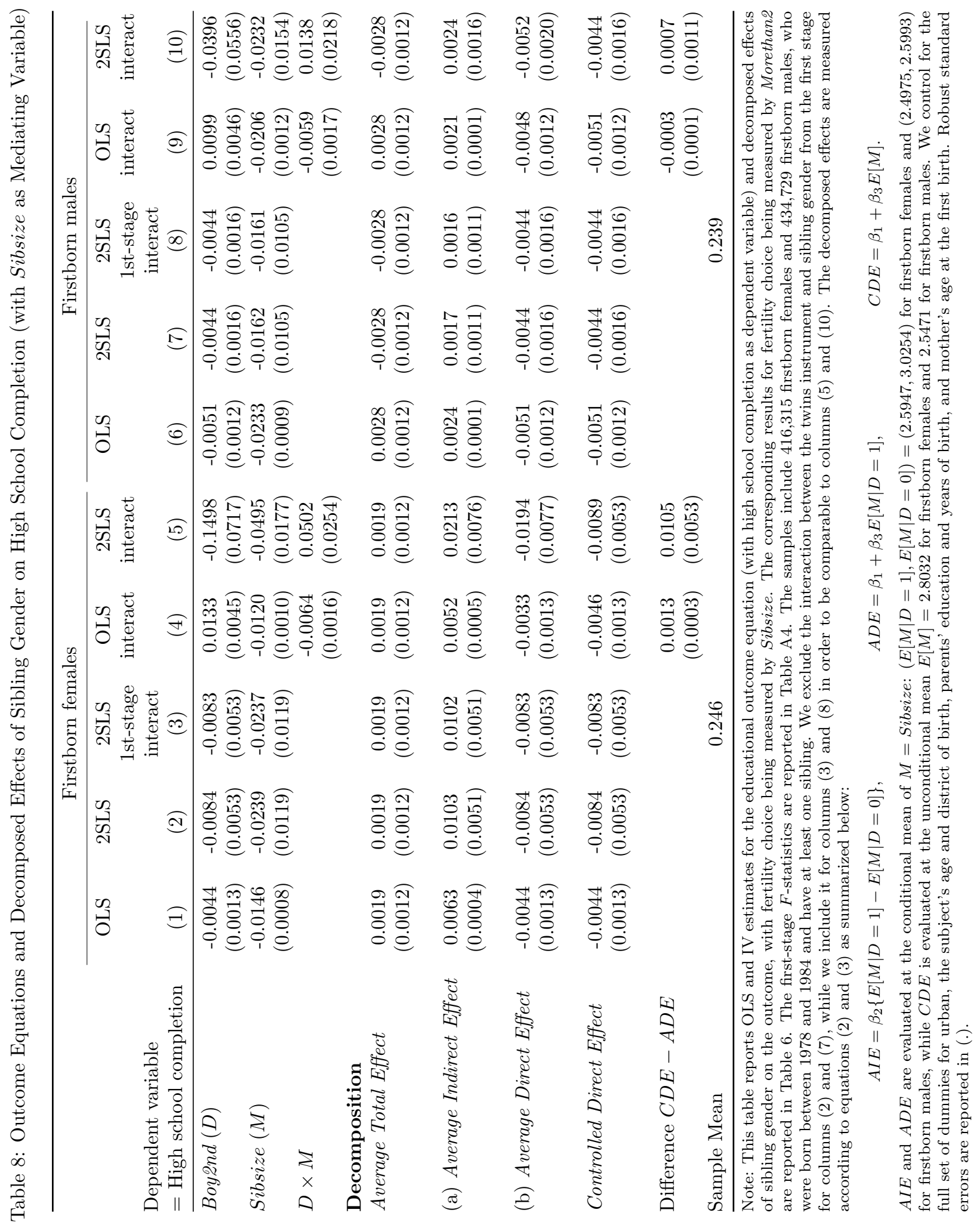




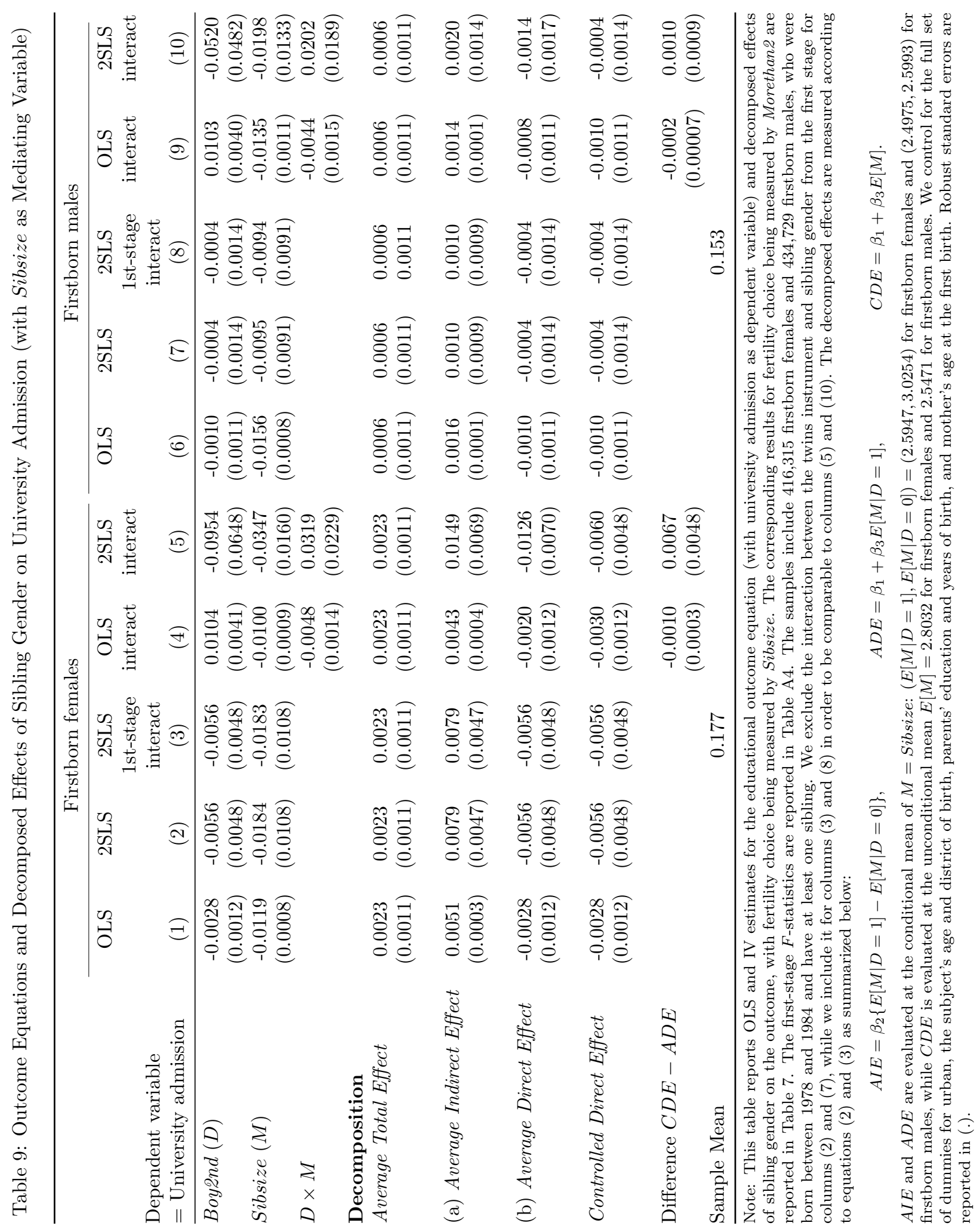




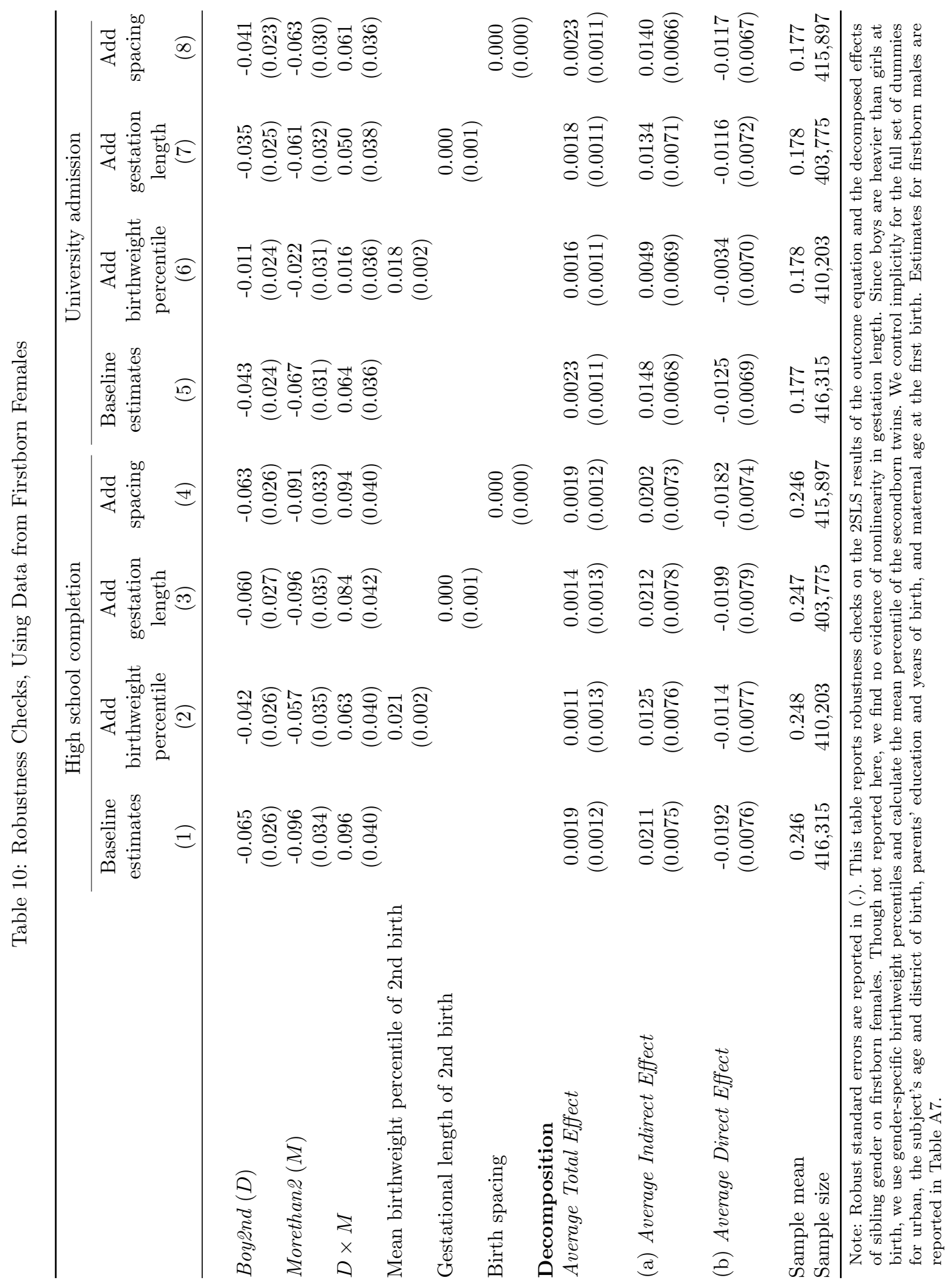


Table 11: Heterogeneous Decomposed Effects on First Child's Education

\begin{tabular}{|c|c|c|c|c|c|c|c|c|}
\hline & \multicolumn{4}{|c|}{ Firstborn females } & \multicolumn{4}{|c|}{ Firstborn males } \\
\hline & $\begin{array}{l}\mathrm{HS} \\
(1)\end{array}$ & $\begin{array}{l}\text { Univ } \\
(2)\end{array}$ & $\begin{array}{l}\mathrm{HS} \\
(3)\end{array}$ & $\begin{array}{c}\text { Univ } \\
(4)\end{array}$ & $\begin{array}{l}\mathrm{HS} \\
(5)\end{array}$ & $\begin{array}{l}\text { Univ } \\
(6)\end{array}$ & $\begin{array}{l}\mathrm{HS} \\
(7)\end{array}$ & $\begin{array}{c}\text { Univ } \\
(8)\end{array}$ \\
\hline & \multicolumn{2}{|c|}{ Father HS+ } & \multicolumn{2}{|c|}{ Father HS- } & \multicolumn{2}{|c|}{ Father HS+ } & \multicolumn{2}{|c|}{ Father HS- } \\
\hline Sample mean & 0.377 & 0.277 & 0.152 & 0.105 & 0.369 & 0.240 & 0.146 & 0.091 \\
\hline Average Total Effect/Mean & $\begin{array}{c}0.010 \\
(0.006)\end{array}$ & $\begin{array}{c}0.012 \\
(0.007)\end{array}$ & $\begin{array}{c}0.005 \\
(0.009)\end{array}$ & $\begin{array}{c}0.017 \\
(0.012)\end{array}$ & $\begin{array}{l}-0.008 \\
(0.006)\end{array}$ & $\begin{array}{c}0.007 \\
(0.008)\end{array}$ & $\begin{array}{c}-0.019 \\
(0.009)\end{array}$ & $\begin{array}{l}-0.003 \\
(0.012)\end{array}$ \\
\hline (a) Average Indirect Effect/Mean & $\begin{array}{c}0.098 \\
(0.028)\end{array}$ & $\begin{array}{c}0.100 \\
(0.036)\end{array}$ & $\begin{array}{c}0.013 \\
(0.072)\end{array}$ & $\begin{array}{l}-0.007 \\
(0.090)\end{array}$ & $\begin{array}{c}0.005 \\
(0.004)\end{array}$ & $\begin{array}{c}0.009 \\
(0.006)\end{array}$ & $\begin{array}{c}0.010 \\
(0.014)\end{array}$ & $\begin{array}{c}0.006 \\
(0.018)\end{array}$ \\
\hline \multirow[t]{2}{*}{ (b) Average Direct Effect/Mean } & $\begin{array}{l}-0.088 \\
(0.029)\end{array}$ & $\begin{array}{l}-0.088 \\
(0.036)\end{array}$ & $\begin{array}{l}-0.009 \\
(0.073)\end{array}$ & $\begin{array}{c}0.024 \\
(0.091)\end{array}$ & $\begin{array}{l}-0.013 \\
(0.007)\end{array}$ & $\begin{array}{l}-0.002 \\
(0.010)\end{array}$ & $\begin{array}{l}-0.029 \\
(0.017)\end{array}$ & $\begin{array}{l}-0.009 \\
(0.022)\end{array}$ \\
\hline & \multicolumn{2}{|c|}{ Mother HS+ } & \multicolumn{2}{|c|}{ Mother HS- } & \multicolumn{2}{|c|}{ Mother HS+ } & \multicolumn{2}{|c|}{ Mother HS- } \\
\hline Sample mean & 0.415 & 0.307 & 0.164 & 0.114 & 0.401 & 0.265 & 0.160 & 0.099 \\
\hline Average Total Effect/Mean & $\begin{array}{c}0.003 \\
(0.006)\end{array}$ & $\begin{array}{c}0.002 \\
(0.008)\end{array}$ & $\begin{array}{c}0.013 \\
(0.008)\end{array}$ & $\begin{array}{c}0.027 \\
(0.010)\end{array}$ & $\begin{array}{c}0.008 \\
(0.006)\end{array}$ & $\begin{array}{c}0.002 \\
(0.009)\end{array}$ & $\begin{array}{c}-0.016 \\
(0.008)\end{array}$ & $\begin{array}{c}0.007 \\
(0.011)\end{array}$ \\
\hline (a) Average Indirect Effect/Mean & $\begin{array}{c}0.082 \\
(0.026)\end{array}$ & $\begin{array}{c}0.072 \\
(0.033)\end{array}$ & $\begin{array}{c}0.043 \\
(0.066)\end{array}$ & $\begin{array}{c}0.064 \\
(0.082)\end{array}$ & $\begin{array}{c}0.001 \\
(0.003)\end{array}$ & $\begin{array}{c}0.000 \\
(0.005)\end{array}$ & $\begin{array}{c}0.026 \\
(0.012)\end{array}$ & $\begin{array}{c}0.033 \\
(0.016)\end{array}$ \\
\hline \multirow[t]{2}{*}{ (b) Average Direct Effect/Mean } & $\begin{array}{l}-0.079 \\
(0.027)\end{array}$ & $\begin{array}{l}-0.070 \\
(0.034)\end{array}$ & $\begin{array}{l}-0.030 \\
(0.066)\end{array}$ & $\begin{array}{l}-0.037 \\
(0.083)\end{array}$ & $\begin{array}{c}0.007 \\
(0.007)\end{array}$ & $\begin{array}{c}0.001 \\
(0.010)\end{array}$ & $\begin{array}{l}-0.043 \\
(0.015)\end{array}$ & $\begin{array}{l}-0.026 \\
(0.019)\end{array}$ \\
\hline & \multicolumn{2}{|c|}{ Urban } & \multicolumn{2}{|c|}{ Rural } & \multicolumn{2}{|c|}{ Urban } & \multicolumn{2}{|c|}{ Rural } \\
\hline Sample mean & 0.298 & 0.216 & 0.219 & 0.157 & 0.281 & 0.181 & 0.217 & 0.139 \\
\hline Average Total Effect/Mean & $\begin{array}{c}0.009 \\
(0.008)\end{array}$ & $\begin{array}{c}0.014 \\
(0.010)\end{array}$ & $\begin{array}{c}0.007 \\
(0.007)\end{array}$ & $\begin{array}{c}0.012 \\
(0.008)\end{array}$ & $\begin{array}{l}-0.014 \\
(0.008)\end{array}$ & $\begin{array}{l}-0.006 \\
(0.011)\end{array}$ & $\begin{array}{l}-0.010 \\
(0.007)\end{array}$ & $\begin{array}{c}0.010 \\
(0.009)\end{array}$ \\
\hline (a) Average Indirect Effect/Mean & $\begin{array}{c}0.076 \\
(0.034)\end{array}$ & $\begin{array}{c}0.106 \\
(0.043)\end{array}$ & $\begin{array}{c}0.095 \\
(0.050)\end{array}$ & $\begin{array}{c}0.051 \\
(0.063)\end{array}$ & $\begin{array}{c}0.002 \\
(0.005)\end{array}$ & $\begin{array}{c}0.003 \\
(0.007)\end{array}$ & $\begin{array}{c}0.016 \\
(0.009)\end{array}$ & $\begin{array}{c}0.020 \\
(0.013)\end{array}$ \\
\hline (b) Average Direct Effect/Mean & $\begin{array}{l}-0.067 \\
(0.035)\end{array}$ & $\begin{array}{l}-0.092 \\
(0.044)\end{array}$ & $\begin{array}{l}-0.088 \\
(0.051)\end{array}$ & $\begin{array}{l}-0.039 \\
(0.064)\end{array}$ & $\begin{array}{l}-0.016 \\
(0.009)\end{array}$ & $\begin{array}{l}-0.009 \\
(0.013)\end{array}$ & $\begin{array}{c}-0.026 \\
(0.011)\end{array}$ & $\begin{array}{c}-0.010 \\
(0.015)\end{array}$ \\
\hline
\end{tabular}

Note: This table reports the IV estimated decomposed effects of having a second born brother on the first child's high school completion (HS) and university admission (Univ), by place of birth (urban versus rural) and by maternal/paternal education ((academic or vocational) high school diploma or more (HS+) versus less high school (HS-)). M = Morethan2; results using Sibsize are almost identical. Robust standard errors are in (.). We control for the full set of indicators for urban, the subject's age and district of birth, parents' education and years of birth, and maternal age at the first birth. The decomposed effects are evaluated at the conditional means of $M=$ Morethan2; that is, $E[M \mid D=1], E[M \mid D=0]$ in the corresponding subgroup. 


\section{Appendix: Sample Analogs of Average Direct and Indirect Effects}

This appendix shows how we derive equations (2) and (3). Let $M_{1}$ and $M_{0}$ denote the potential sibsize as if the next sibling were male or female respectively, regardless of the realized gender. Motivated by VanderWeele's $(2013,2014)$ causal inference methods, we decompose the total effect $(T E)$ of sibling gender into $D E$ and $I E$ as follows. We suppress the notation for firstborn gender (and other covariates) for ease of exposition.

$$
\begin{array}{ll}
D E\left(M_{1}\right) & =E\left[Y \mid M_{1}, D=1\right]-E\left[Y \mid M_{1}, D=0\right], \\
I E\left(M_{1}, M_{0}\right) & =E\left[Y \mid M_{1}, D=0\right]-E\left[Y \mid M_{0}, D=0\right], \\
T E\left(M_{1}, M_{0}\right) & =E\left[Y \mid M_{1}, D=1\right]-E\left[Y \mid M_{0}, D=0\right] .
\end{array}
$$

We measure $D E$ by fixing potential sibsize $M_{1}$ as if the gender of the next sibling were always male, and $I E$ through changing potential sibsize by switching the gender of the next sibling. The sum of $D E$ and $I E$ is the total influence of a change in sibling gender on the firstborn. Given the son-preferring stopping rules, potential sibsize increases with a female second birth; that is, $M_{0}>M_{1}$ and $M>M_{1}$. Therefore, $D E$ is not necessarily equal to $C D E=E[Y \mid M, D=1]-E[Y \mid M, D=0]$.

Under the assumption of randomized sibling gender, we find two useful properties to proceed:

Property (1): $\epsilon_{1 M}$ and $\epsilon_{0 M}$ share the same distribution, conditional on sibsize $M$.

This implies $E\left[\epsilon_{1 M}-\epsilon_{0 M} \mid M=m\right]=0$ for any sibsize $m$.

Property (2): Observed and potential sibsizes share the same distribution conditional on sibling gender.

This implies $E\left[M_{D}\right]=E[M \mid D=d]$ for $d=0$ or 1 .

Using these two properties, we can construct the sample analogs of $D E$ and $I E$ by averaging over all possible values of potential sibsize in $\mathcal{M}$. We start with $A D E$, standing for the sample analogs of $D E$ :

$$
\begin{aligned}
A D E & =\Sigma_{m \in \mathcal{M}}\left\{E\left[Y \mid M_{1}, D=1\right]-E\left[Y \mid M_{1}, D=0\right]\right\} \operatorname{Pr}\left\{M_{1}=m \mid D=1\right\} \\
& =\Sigma_{m \in \mathcal{M}} E\left[\left(\beta_{0}+\beta_{1}+\beta_{2} M_{1}+\beta_{3} M_{1}+\epsilon_{1 M}\right)-\left(\beta_{0}+\beta_{2} M_{1}+\epsilon_{0 M}\right)\right] \operatorname{Pr}\left\{M_{1}=m \mid D=1\right\} \\
& =\beta_{1}+\beta_{3} E[M \mid D=1]+\Sigma_{m \in \mathcal{M}} E\left[\epsilon_{1 M}-\epsilon_{0 M} \mid M=m\right] \operatorname{Pr}\{M=m \mid D=1\} \\
& =\beta_{1}+\beta_{3} E[M \mid D=1] .
\end{aligned}
$$

The second equality is achieved by applying equation (1). The third and fourth equalities are achieved by using Property (2) and Property (1) respectively. The sample analog of $I E$ (denoted by $A I E$ ) can be derived similarly. 
Table A1: Differences in Unconditional Means for Demographics, by Boy2nd and Twin2nd

\begin{tabular}{|c|c|c|c|c|}
\hline \multirow[b]{3}{*}{ Demographic variables } & \multicolumn{4}{|c|}{ Difference in Means } \\
\hline & \multicolumn{2}{|c|}{ By Boy2nd } & \multicolumn{2}{|c|}{ By Twin2nd } \\
\hline & $\begin{array}{r}\text { Firstborn } \\
\text { female } \\
(1)\end{array}$ & $\begin{array}{r}\text { Firstborn } \\
\text { male } \\
(2)\end{array}$ & $\begin{array}{r}\text { Firstborn } \\
\text { female } \\
(3)\end{array}$ & $\begin{array}{r}\text { Firstborn } \\
\text { male } \\
(4)\end{array}$ \\
\hline Urban (firstborn's birthplace) & 0.0014 & -0.0002 & 0.0140 & $0.0285^{*}$ \\
\hline Mother has univ./professional degree+ & $0.0020^{*}$ & -0.0002 & $0.0175^{*}$ & $0.0116^{*}$ \\
\hline Father has univ./professional degree+ & $0.0023^{*}$ & 0.0013 & $0.0164^{*}$ & $0.0220^{*}$ \\
\hline Mother's age at first birth & $0.034^{*}$ & 0.001 & $0.339^{*}$ & $0.447^{*}$ \\
\hline Mother's year of birth & $-0.041^{*}$ & 0.007 & $-0.146^{*}$ & $-0.317^{*}$ \\
\hline Father's year of birth & -0.015 & 0.010 & -0.044 & -0.087 \\
\hline
\end{tabular}

Note: This table reports the difference in means for demographic variables by Boy2nd or Twin2nd, conditional on firstborn gender. The samples include 416,315 firstborn females and 434,729 firstborn males, who were born between 1978 and 1984 and have at least one sibling. * indicates the $5 \%$ significance level.

Table A2: Difference in Conditional Means for Demographics, by Boy2nd and Twin2nd (OLS Results)

\begin{tabular}{|c|c|c|c|c|}
\hline \multirow[b]{2}{*}{ Demographic variables } & \multicolumn{2}{|c|}{ Dependent variable $=$ Boy2nd } & \multicolumn{2}{|c|}{ Dependent variable $=$ Twin2na } \\
\hline & $\begin{array}{r}\text { Firstborn } \\
\text { female } \\
(1)\end{array}$ & $\begin{array}{r}\text { Firstborn } \\
\text { male } \\
(2)\end{array}$ & $\begin{array}{r}\text { Firstborn } \\
\text { female } \\
(3)\end{array}$ & $\begin{array}{r}\text { Firstborn } \\
\text { male } \\
(4)\end{array}$ \\
\hline Urban (firstborn's birthplace) & 0.014 & -0.029 & -0.010 & -0.006 \\
\hline Parental education, dummies & Yes & Yes & Yes & Yes \\
\hline [p-value] & {$[0.20]$} & {$[0.20]$} & {$[0.15]$} & {$[0.14]$} \\
\hline Mother's age at first birth & -0.0001 & 0.0001 & $0.0005^{*}$ & $0.0004^{*}$ \\
\hline Mother's year of birth & -0.0008 & 0.0003 & $0.0003^{*}$ & 0.0001 \\
\hline Father's year of birth & 0.0003 & 0.0001 & 0.0000 & 0.0000 \\
\hline District fixed effects & Yes & Yes & Yes & Yes \\
\hline
\end{tabular}

Note: This table reports the OLS estimated coefficient, by firstborn gender, in regressions of Boy2nd or Twin2nd on covariates, including the district fixed effects for firstborn birthplace. The samples include 416,315 firstborn females and 434,729 firstborn males, who were born between 1978 and 1984 and have at least one sibling. Parental education dummies include the 10 indicators for both mother's and father's highest qualifications: university degree+, professional degree, high school diploma, vocational high school, and junior high school, using primary education or below as the reference group. P-values for the joint test for the significance of the parental education dummies are reported in [.]. * indicates the $5 \%$ significance level. 


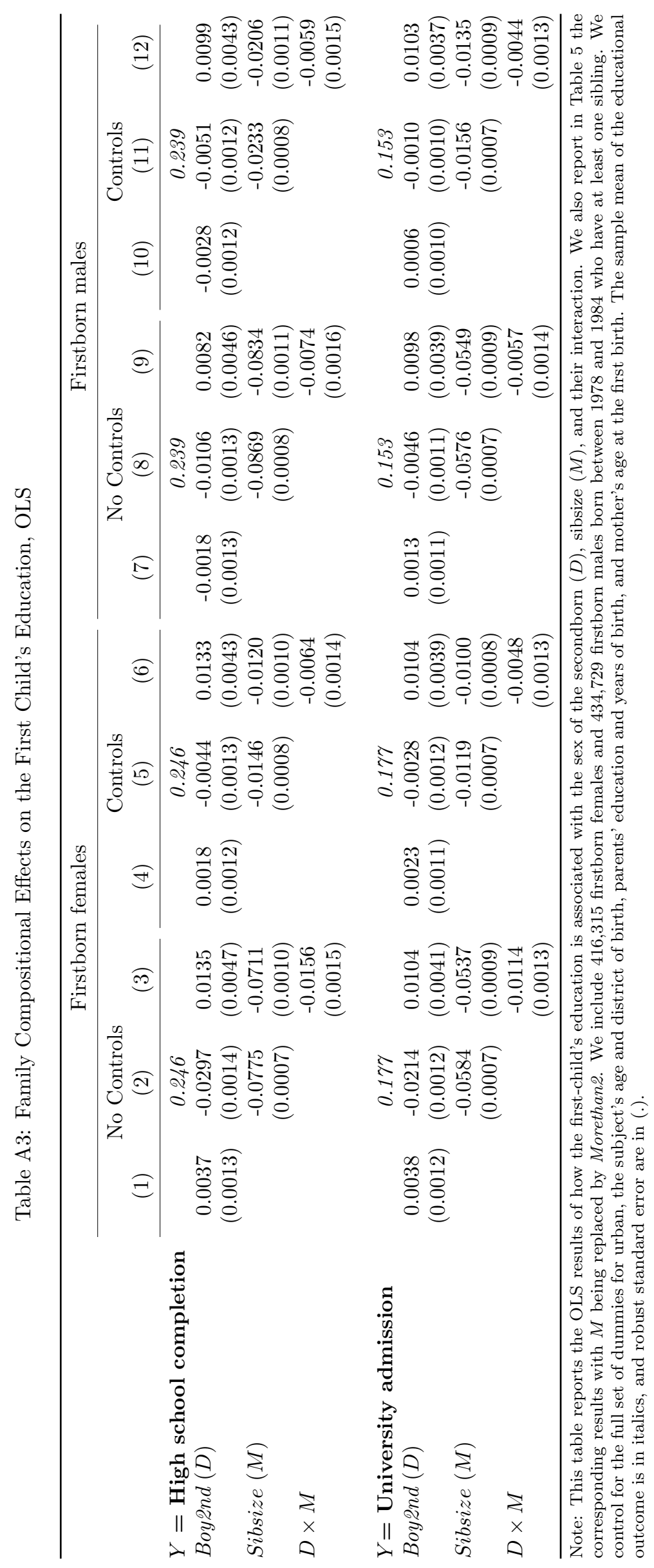


Table A4: First-Stage Estimates

\begin{tabular}{|c|c|c|c|c|}
\hline & \multicolumn{2}{|c|}{ Firstborn females } & \multicolumn{2}{|c|}{ Firstborn males } \\
\hline & (1) & $(2)$ & $(3)$ & $(4)$ \\
\hline 1) Dependent Variable $=$ Morethan2 & 0.59 & 0.59 & 0.45 & 0.45 \\
\hline Boy2nd & $\begin{array}{l}-0.219 \\
(0.001)\end{array}$ & $\begin{array}{c}-0.221 \\
(0.001)\end{array}$ & $\begin{array}{c}-0.063 \\
(0.001)\end{array}$ & $\begin{array}{c}-0.064 \\
(0.001)\end{array}$ \\
\hline Twin2nd & $\begin{array}{c}0.436 \\
(0.004)\end{array}$ & $\begin{array}{c}0.322 \\
(0.005)\end{array}$ & $\begin{array}{c}0.572 \\
(0.003)\end{array}$ & $\begin{array}{c}0.539 \\
(0.005)\end{array}$ \\
\hline Twin2nd $\times$ Boy2nd & & $\begin{array}{c}0.223 \\
(0.007)\end{array}$ & & $\begin{array}{c}0.067 \\
(0.007)\end{array}$ \\
\hline$F$-statistic for twins effect & 11,973 & 8,680 & 27,123 & 14,081 \\
\hline Multivariate first-stage $F$-statistic & & 2,046 & & 5,892 \\
\hline 2) Dependent Variable $=$ Morethan $2 \times$ Boy $2 n d$ & & & & \\
\hline Boy2nd & $\begin{array}{c}0.480 \\
(0.001)\end{array}$ & $\begin{array}{c}0.476 \\
(0.001)\end{array}$ & $\begin{array}{c}0.419 \\
(0.001)\end{array}$ & $\begin{array}{c}0.416 \\
(0.001)\end{array}$ \\
\hline Twin2nd & $\begin{array}{c}0.278 \\
(0.005)\end{array}$ & $\begin{array}{c}0.011 \\
(0.003)\end{array}$ & $\begin{array}{c}0.305 \\
(0.006)\end{array}$ & $\begin{array}{c}0.010 \\
(0.002)\end{array}$ \\
\hline Twin2nd $\times$ Boy2nd & & $\begin{array}{c}0.526 \\
(0.004)\end{array}$ & & $\begin{array}{c}0.586 \\
(0.003)\end{array}$ \\
\hline$F$-statistic for twins effect & 2,875 & 19,251 & 2,797 & 27,981 \\
\hline Multivariate first-stage $F$-statistic & & 5,110 & & 12,866 \\
\hline 3) Dependent Variable $=$ Sibsize & 2.80 & 2.80 & 2.55 & 2.55 \\
\hline Boy2nd & $\begin{array}{l}-0.428 \\
(0.002)\end{array}$ & $\begin{array}{c}-0.428 \\
(0.002)\end{array}$ & $\begin{array}{l}-0.101 \\
(0.002)\end{array}$ & $\begin{array}{l}-0.101 \\
(0.002)\end{array}$ \\
\hline Twin2nd & $\begin{array}{c}0.622 \\
(0.012)\end{array}$ & $\begin{array}{c}0.616 \\
(0.019)\end{array}$ & $\begin{array}{c}0.720 \\
(0.010)\end{array}$ & $\begin{array}{c}0.711 \\
(0.014)\end{array}$ \\
\hline Twin2nd $\times$ Boy2nd & & $\begin{array}{c}0.012 \\
(0.024)\end{array}$ & & $\begin{array}{c}0.018 \\
(0.020)\end{array}$ \\
\hline$F$-statistic for twins effect & 2,817 & 1,568 & 5,285 & 2,649 \\
\hline Multivariate first-stage $F$-statistic & & 488 & & 1,191 \\
\hline 4) Dependent Variable $=$ Sibsize $\times$ Boy2nd & & & & \\
\hline Boy2nd & $\begin{array}{c}2.596 \\
(0.002)\end{array}$ & $\begin{array}{c}2.592 \\
(0.002)\end{array}$ & $\begin{array}{c}2.498 \\
(0.001)\end{array}$ & $\begin{array}{c}2.493 \\
(0.001)\end{array}$ \\
\hline Twin2nd & $\begin{array}{c}0.317 \\
(0.009)\end{array}$ & $\begin{array}{c}0.015 \\
(0.004)\end{array}$ & $\begin{array}{c}0.367 \\
(0.010)\end{array}$ & $\begin{array}{c}0.013 \\
(0.003)\end{array}$ \\
\hline Twin2nd $\times$ Boy2nd & & $\begin{array}{c}0.593 \\
(0.013)\end{array}$ & & $\begin{array}{c}0.701 \\
(0.014)\end{array}$ \\
\hline$F$-statistic for twins effect & 1,372 & 1,203 & 1,489 & 1,474 \\
\hline Multivariate first-stage $F$-statistic & & 3,472 & & 6,300 \\
\hline
\end{tabular}

Note: Panels (1) and (3) of this table report the first-stage estimates for fertility choice, using twinning at the second birth (Twin2nd) as instrument. Panels (2) and (4) report the first-stage estimates for the interaction between fertility choice and Boy2nd, using Twin2nd $\times$ Boy2nd as instrument. An interaction term for Twin2nd $\times$ Boy2nd is included in Columns (2) and (4) when the interaction between fertility choice and Boy2nd is included in the outcome equation. We include 416,315 firstborn females and 434,729 firstborn males born between 1978 and 1984 who have at least one sibling. Additional covariates include the full set of indicators for urban, the subject's age and district of birth, parents' education and years of birth, and mother's age at the first birth. The multivariate first-stage $F$-statistics are constructed as described in Angrist and Pischke (2009, pp. 217-18). Means of the fertility choice variable are in italics, and robust standard errors are in (.). 
Table A5: Reduced-Form Results

\begin{tabular}{|c|c|c|c|c|}
\hline & \multicolumn{2}{|c|}{ Firstborn females } & \multicolumn{2}{|c|}{ Firstborn males } \\
\hline & $(1)$ & $(2)$ & $(3)$ & $(4)$ \\
\hline$Y=$ High school completion & & 0.246 & & 0.239 \\
\hline Boy2nd & $\begin{array}{c}0.0018 \\
(0.0012)\end{array}$ & $\begin{array}{c}0.0016 \\
(0.0012)\end{array}$ & $\begin{array}{l}-0.0028 \\
(0.0012)\end{array}$ & $\begin{array}{c}-0.0028 \\
(0.0012)\end{array}$ \\
\hline Twin2nd & $\begin{array}{l}-0.0149 \\
(0.0075)\end{array}$ & $\begin{array}{l}-0.0297 \\
(0.0107)\end{array}$ & $\begin{array}{l}-0.0117 \\
(0.0076)\end{array}$ & $\begin{array}{l}-0.0163 \\
(0.0107)\end{array}$ \\
\hline Twin $2 n d \times$ Boy $2 n d$ & & $\begin{array}{c}0.0292 \\
(0.0150)\end{array}$ & & $\begin{array}{c}0.0093 \\
(0.0152)\end{array}$ \\
\hline$Y=$ University admission & & 0.177 & & 0.153 \\
\hline Boy2nd & $\begin{array}{c}0.0023 \\
(0.0011)\end{array}$ & $\begin{array}{c}0.0021 \\
(0.0011)\end{array}$ & $\begin{array}{c}0.0006 \\
(0.0011)\end{array}$ & $\begin{array}{c}0.0005 \\
(0.0011)\end{array}$ \\
\hline Twin2nd & $\begin{array}{l}-0.0115 \\
(0.0068)\end{array}$ & $\begin{array}{c}-0.0209 \\
(0.0096)\end{array}$ & $\begin{array}{c}-0.0068 \\
(0.0066)\end{array}$ & $\begin{array}{l}-0.0138 \\
(0.0092)\end{array}$ \\
\hline Twin $2 n d \times$ Boy $2 n d$ & & $\begin{array}{c}0.0185 \\
(0.0135)\end{array}$ & & $\begin{array}{c}0.0138 \\
(0.0132)\end{array}$ \\
\hline
\end{tabular}

Note: This table reports the reduced-form results by firstborn gender. We regress the educational outcomes on Boy2nd, Twin2nd, and their interaction, in addition to the full set of indicators for urban, the subject's age and district of birth, parents' education and years of birth, and maternal age at the first birth. The samples include 416,315 firstborn females and 434,729 firstborn males, who were born between 1978 and 1984 and have at least one sibling. Robust standard errors are reported in (.) and sample means in italics.

Table A6: Family Size and Initial Health Conditions of the Secondborn

\begin{tabular}{lcccr}
\hline $\begin{array}{l}\text { Family } \\
\text { size }\end{array}$ & $\begin{array}{c}\text { Mean } \\
\text { gestational } \\
\text { length }\end{array}$ & $\begin{array}{c}\text { Mean } \\
\text { birthweight }\end{array}$ & $\begin{array}{c}\text { Mean } \\
\text { birthweight } \\
\text { percentile }\end{array}$ & $\begin{array}{r}\text { Number } \\
\text { of families }\end{array}$ \\
\hline 2 & 39.571 & 3.301 & 0.515 & 406,255 \\
3 & 39.669 & 3.267 & 0.501 & 328,111 \\
4 & 39.675 & 3.233 & 0.490 & 84,418 \\
5 & 39.672 & 3.210 & 0.482 & 15,812 \\
6 & 39.669 & 3.203 & 0.478 & 3,198 \\
7 & 39.697 & 3.183 & 0.462 & 674 \\
8 & 39.667 & 3.196 & 0.473 & 168 \\
9 or more & 39.820 & 3.187 & 0.461 & 60 \\
All sample & 39.623 & 3.279 & 0.506 & 838,696 \\
\hline
\end{tabular}

Note: This table reports relationship between family size and the initial health conditions of the secondborn whose oldest sibling was born between 1978 and 1984. Birthweight is in kilograms and birthweight percentiles are calculated given the child's gender. We calculate the mean if the secondborn is twins. This data has fewer observations than the firstborn population in Table 1 since some secondborn children have no information about initial health conditions. 


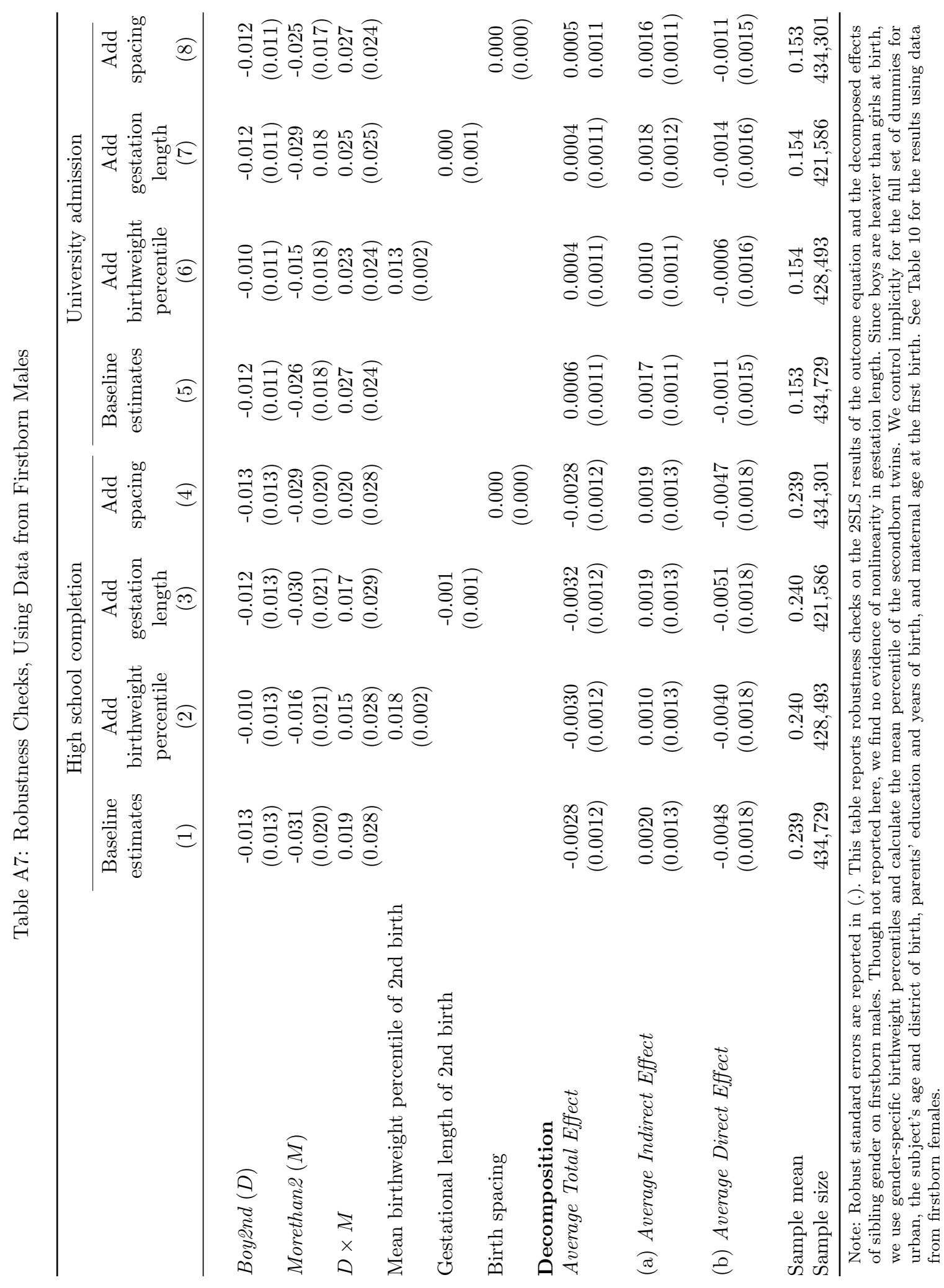


Table A8: Earlier Models of Sibling Rivalry, Using Taiwanese Birth Data Including All Parities

\begin{tabular}{|c|c|c|c|c|c|c|}
\hline & \multicolumn{3}{|c|}{ Females } & \multicolumn{3}{|c|}{ Males } \\
\hline & $\begin{array}{c}\text { Parish } \\
\text { \& Willis } \\
(1993, \text { t3) } \\
(1)\end{array}$ & $\begin{array}{c}\text { Garg } \\
\text { \& Morduch } \\
(1998, \mathrm{t} 2) \\
(2)\end{array}$ & $\begin{array}{c}\text { Butcher } \\
\text { \& Case } \\
(1994, \text { t5) } \\
(3)\end{array}$ & $\begin{array}{c}\text { Parish } \\
\text { \& Willis } \\
(1993, \text { t3) } \\
(4)\end{array}$ & $\begin{array}{c}\text { Garg } \\
\text { \& Morduch } \\
(1998, \text { t2) } \\
(5)\end{array}$ & $\begin{array}{c}\text { Butcher } \\
\text { \& Case } \\
(1994, \mathrm{t} 5) \\
(6)\end{array}$ \\
\hline $\mathbf{Y}=$ High school completion & 0.172 & 0.172 & 0.172 & 0.178 & 0.178 & 0.178 \\
\hline Number of younger brothers & $\begin{array}{c}-0.0039 \\
(0.0006)\end{array}$ & & & $\begin{array}{l}-0.0122 \\
(0.0006)\end{array}$ & & \\
\hline Number of younger sisters & $\begin{array}{l}-0.0064 \\
(0.0005)\end{array}$ & & & $\begin{array}{l}-0.0075 \\
(0.0006)\end{array}$ & & \\
\hline Number of older brothers & $\begin{array}{c}-0.0053 \\
(0.0112)\end{array}$ & & & $\begin{array}{c}-0.0083 \\
(0.0101)\end{array}$ & & \\
\hline Number of older sisters & $\begin{array}{l}-0.0052 \\
(0.0112)\end{array}$ & & & $\begin{array}{l}-0.0081 \\
(0.0101)\end{array}$ & & \\
\hline Any brother & & $\begin{array}{c}0.0189 \\
(0.0012)\end{array}$ & $\begin{array}{c}0.0095 \\
(0.0008)\end{array}$ & & $\begin{array}{c}0.0078 \\
(0.0012)\end{array}$ & $\begin{array}{l}-0.0001 \\
(0.0007)\end{array}$ \\
\hline Family size & & $\begin{array}{l}-0.0137 \\
(0.0008)\end{array}$ & $\begin{array}{l}-0.0071 \\
(0.0004)\end{array}$ & & $\begin{array}{l}-0.0156 \\
(0.0008)\end{array}$ & $\begin{array}{l}-0.0102 \\
(0.0005)\end{array}$ \\
\hline Number of sisters & & $\begin{array}{c}0.0078 \\
(0.0008)\end{array}$ & & & $\begin{array}{c}0.0068 \\
(0.0008)\end{array}$ & \\
\hline $\mathbf{Y}=$ University admission & 0.120 & 0.120 & 0.120 & 0.116 & 0.116 & 0.116 \\
\hline Number of younger brothers & $\begin{array}{l}-0.0029 \\
(0.0005)\end{array}$ & & & $\begin{array}{c}-0.0073 \\
(0.0005)\end{array}$ & & \\
\hline Number of younger sisters & $\begin{array}{l}-0.0045 \\
(0.0004)\end{array}$ & & & $\begin{array}{l}-0.0054 \\
(0.0005)\end{array}$ & & \\
\hline Number of older brothers & $\begin{array}{l}-0.0084 \\
(0.0098)\end{array}$ & & & $\begin{array}{l}-0.0058 \\
(0.0086)\end{array}$ & & \\
\hline Number of older sisters & $\begin{array}{l}-0.0075 \\
(0.0098)\end{array}$ & & & $\begin{array}{l}-0.0068 \\
(0.0086)\end{array}$ & & \\
\hline Any brother & & $\begin{array}{c}0.0135 \\
(0.0011)\end{array}$ & $\begin{array}{c}0.0062 \\
(0.0007)\end{array}$ & & $\begin{array}{c}0.0063 \\
(0.0010)\end{array}$ & $\begin{array}{c}0.0017 \\
(0.0006)\end{array}$ \\
\hline Family size & & $\begin{array}{l}-0.0102 \\
(0.0007)\end{array}$ & $\begin{array}{l}-0.0050 \\
(0.0004)\end{array}$ & & $\begin{array}{l}-0.0102 \\
(0.0007)\end{array}$ & $\begin{array}{l}-0.0071 \\
(0.0004)\end{array}$ \\
\hline Number of sisters & & $\begin{array}{c}0.0061 \\
(0.0007)\end{array}$ & & & $\begin{array}{c}0.0039 \\
(0.0007)\end{array}$ & \\
\hline Sample size & $1,148,793$ & $1,148,793$ & $1,148,793$ & $1,242,095$ & $1,242,095$ & $1,242,095$ \\
\hline
\end{tabular}

Note: Sample mean of the corresponding educational outcome is reported in italics, and robust standard errors in (.). This table reports the OLS results in Parish and Willis (1993 table 3), Garg and Morduch (1998 table 2), and Butcher and Case (1994 table 5 ), using birth registry data of all Taiwanese families whose first child is singleton and born between 1978 and 1984 . We control for the full set of dummies for urban, the subject's age and district of birth, parents' education and years of birth, and maternal age at the first birth. For the regressions that include only firstborn children are reported in Table A9. 
Table A9: Earlier Models of Sibling Rivalry, Using Taiwanese Firstborns

\begin{tabular}{|c|c|c|c|c|c|c|}
\hline & \multicolumn{3}{|c|}{ Firstborn females } & \multicolumn{3}{|c|}{ Firstborn males } \\
\hline & $\begin{array}{c}\text { Parish } \\
\text { \& Willis } \\
(1993, \text { t3) } \\
(1)\end{array}$ & $\begin{array}{c}\text { Garg } \\
\text { \& Morduch } \\
(1998, \text { t2) } \\
(2)\end{array}$ & $\begin{array}{c}\text { Butcher } \\
\text { \& Case } \\
(1994, \text { t5 }) \\
(3)\end{array}$ & $\begin{array}{c}\text { Parish } \\
\text { \& Willis } \\
(1993, \text { t3) } \\
(4)\end{array}$ & $\begin{array}{c}\text { Garg } \\
\text { \& Morduch } \\
(1998, \mathrm{t} 2) \\
(5)\end{array}$ & $\begin{array}{c}\text { Butcher } \\
\text { \& Case } \\
(1994, \text { t5 }) \\
(6)\end{array}$ \\
\hline $\begin{array}{l}\mathbf{Y}=\text { High school completion } \\
\text { Number of (younger) brothers }\end{array}$ & $\begin{array}{c}0.249 \\
0.0003 \\
(0.0009)\end{array}$ & 0.249 & 0.249 & $\begin{array}{c}0.241 \\
-0.0063 \\
(0.0008)\end{array}$ & 0.241 & 0.241 \\
\hline Number of (younger) sisters & $\begin{array}{l}-0.0034 \\
(0.0007)\end{array}$ & $\begin{array}{c}0.0151 \\
(0.0014)\end{array}$ & & $\begin{array}{l}-0.0024 \\
(0.0008)\end{array}$ & $\begin{array}{c}0.0211 \\
(0.0015)\end{array}$ & \\
\hline Any brother & & $\begin{array}{c}0.0339 \\
(0.0022)\end{array}$ & $\begin{array}{c}0.0169 \\
(0.0014)\end{array}$ & & $\begin{array}{c}0.0271 \\
(0.0021)\end{array}$ & $\begin{array}{c}0.0042 \\
(0.0013)\end{array}$ \\
\hline Family size & & $\begin{array}{l}-0.0182 \\
(0.0014)\end{array}$ & $\begin{array}{l}-0.0052 \\
(0.0007)\end{array}$ & & $\begin{array}{l}-0.0225 \\
(0.0014)\end{array}$ & $\begin{array}{l}-0.0053 \\
(0.0007)\end{array}$ \\
\hline $\begin{array}{l}\mathbf{Y}=\text { University admission } \\
\text { Number of (younger) brothers }\end{array}$ & $\begin{array}{c}0.179 \\
0.0000 \\
(0.0008)\end{array}$ & 0.179 & 0.179 & $\begin{array}{c}0.154 \\
-0.0031 \\
(0.0007)\end{array}$ & 0.154 & 0.154 \\
\hline Number of (younger) sisters & $\begin{array}{c}-0.0028 \\
(0.0006)\end{array}$ & $\begin{array}{c}0.0123 \\
(0.0012)\end{array}$ & & $\begin{array}{c}-0.0020 \\
(0.0007)\end{array}$ & $\begin{array}{c}0.0136 \\
(0.0013)\end{array}$ & \\
\hline Any brother & & $\begin{array}{c}0.0272 \\
(0.0019)\end{array}$ & $\begin{array}{c}0.0134 \\
(0.0013)\end{array}$ & & $\begin{array}{c}0.0198 \\
(0.0018)\end{array}$ & $\begin{array}{c}0.005 \\
(0.0011)\end{array}$ \\
\hline Family size & & $\begin{array}{l}-0.0148 \\
(0.0012)\end{array}$ & $\begin{array}{l}-0.0043 \\
(0.0006)\end{array}$ & & $\begin{array}{l}-0.0149 \\
(0.0012)\end{array}$ & $\begin{array}{l}-0.0038 \\
(0.0006)\end{array}$ \\
\hline Sample size & 466,012 & 466,012 & 466,012 & 499,318 & 499,318 & 499,318 \\
\hline
\end{tabular}

Note: Sample mean of the corresponding educational outcome is reported in italics, and robust standard errors in (.). This table reports the OLS results in Parish and Willis (1993 table 3), Garg and Morduch (1998 table 2), and Butcher and Case (1994 table 5), using population data of Taiwanese firstborn singletons born between 1978 and 1984 . We control for the full set of dummies for urban, the subject's age and district of birth, parents' education and years of birth, and maternal age at the first birth. For regressions that include children at all parities are reported in Table A8. 